Review

\title{
A review of cinnamaldehyde and its derivatives as antibacterial agents
}

\author{
Amanda A. Doyle ${ }^{a}$, John C. Stephens ${ }^{a, b, *}$ \\ ${ }^{a}$ Department of Chemistry, Maynooth University, Maynooth, Co. Kildare, Ireland \\ ${ }^{\mathrm{b}}$ The Kathleen Lonsdale Institute for Human Health Research, Maynooth University, Maynooth, Co. Kildare, Ireland
}

\section{A B S T R A C T}

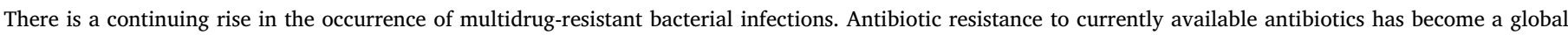

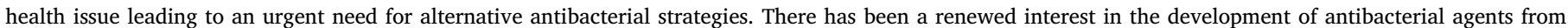

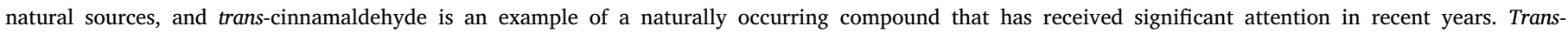

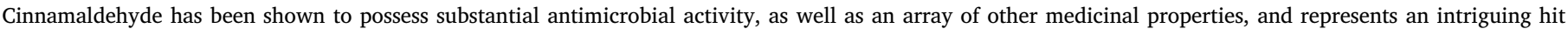

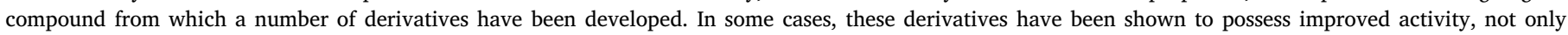

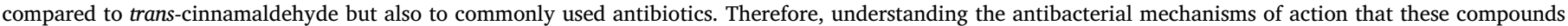

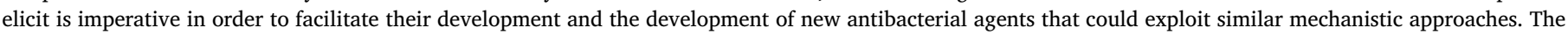

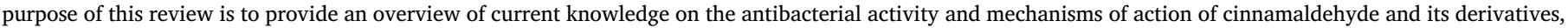

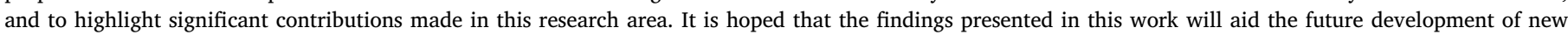
antibacterial agents.

\section{Introduction}

\subsection{Antimicrobial agents}

Antibiotics and antimicrobial agents are those substances that inhibit the growth of bacteria, with many disrupting vital cellular functions thereby causing rapid bacterial cell death [1]. In the last forty years, antibiotics have been over-used by humans, not only by direct consumption but also through their extensive use in animal feed [2]. Consequentially, antibiotic resistance in several pathogenic organisms has occurred [2], with a corresponding reduction in the efficacy of antibiotics that are currently on the market, and has now resulted in antibiotic resistance becoming a global health issue [1]. The American Center for Disease Control and Prevention has reported that more than two million diseases have been caused by microorganisms that are resistant to more than one class of antibiotics [3]. Antibiotic resistance also causes a substantial economic burden, incurring approximately $€ 1.5$ billion in additional health care costs within the European Union [1]. Moreover, this resistance has a high associated mortality rate. Based on data collected between January 1st 2015 and December 31st 2015 , it is estimated that infections involving antibiotic-resistant bacteria accounted for 33,110 attributable deaths in the EU and EEA (European Economic Area) [4]. This high mortality rate is due to the fact that these related infections have become extremely difficult to treat, where examples include extensively drug-resistant tuberculosis
(XDR-TB) and community-associated methicillin-resistant Staphylococcus aureus (MRSA). Such infections pose a monumental challenge to clinicians [2].

\subsection{Natural products}

Aside from the emergence of bacterial antibiotic resistance, negative consumer attitudes toward synthetic food preservatives has meant that the use of natural products, such as plant components containing essential oils and essences, for the purposes of prevention of food spoilage and protection from harmful pathogens has gained increasing consumer popularity $[5,6]$. This consumer trend is in part due to perceived nutritional and safety qualities of natural products [7-9]. As a result, there has been renewed interest by food scientists in the use of spices and natural preservatives derived from plant sources as alternative antimicrobial agents $[7,8]$. Historically, plants, spices, and their essential oils have been used in traditional medicine [10]. From an ecological viewpoint, the use of plants as a source of antimicrobial agents is a sensible strategy because plants naturally produce an array of secondary metabolites that defend the host from microbiological invasion $[3,6]$. In addition, plants can contain chemical entities that have diverse features such as complex structures that synthetically would be difficult to obtain. This may enable these natural antibacterials to elicit different mechanisms of action compared to traditional antibacterial agents [3].

\footnotetext{
* Corresponding author at: Department of Chemistry, Maynooth University, Maynooth, Co. Kildare, Ireland.

E-mail address: john.stephens@mu.ie (J.C. Stephens).
} 
<smiles>O=C/C=C/c1ccccc1</smiles><smiles>O=C/C=C/c1ccccc1OCc1ccccc1</smiles><smiles>O=CC(=Cc1ccccc1)C(C=O)=Cc1ccccc1</smiles><smiles>O=C/C=C/c1ccccc1O</smiles>

$6^{\mathrm{a}}$<smiles>O=C/C=C/c1ccc(O)cc1</smiles><smiles>COc1ccccc1/C=C/C=O</smiles>
$7^{\mathrm{a}}$<smiles>O=C/C=C/c1cc(F)ccc1OC(=O)c1ccccc1</smiles><smiles>COc1cc(/C=C/C=O)ccc1O</smiles>
$15^{\mathrm{a}}$<smiles>O=C/C=C/c1ccc(Cl)c(Cl)c1</smiles>
$19^{\mathrm{b}}$<smiles>O=C/C=C/c1cc(F)ccc1O</smiles><smiles>O=C/C=C/c1ccccc1OC(=O)c1ccccc1</smiles>
$8^{\mathrm{a}}$<smiles>CC(=O)/C=C/c1ccccc1</smiles><smiles>COc1cc(/C=C/C=O)cc(OC)c1O</smiles>
$16^{\mathrm{a}}$

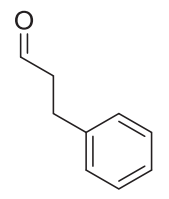

$20^{\mathrm{a}}$

Fig. 1. Examples of cinnamaldehyde derivatives from the literature that have reported medicinal properties, ${ }^{\text {a }}$ denotes a naturally occurring cinnamaldehyde, ${ }^{\mathrm{b}}$ denotes a synthetic cinnamaldehyde derivatives.

\subsection{Cinnamon as a natural product}

Cinnamon spice is obtained from the inner bark of several trees within the genus Cinnamomum, which itself is comprised of approximately 250 plant species [11,12]. The most common species are $C$. cassia (Chinese cinnamon, commonly referred to as Cassia) and $C$. verum (also called C. zeylanicum, commonly referred to as true cinnamon). These two species contain a varying percentage of cinnamaldehyde with up to $85.3 \%$ and $90.5 \%$ reported, respectively [11]. trans-Cinnamaldehyde has been identified as the component that gives rise to much of the reported antimicrobial properties of this spice [9,12-16]. Isolated cinnamaldehyde has been shown to effectively inhibit the growth of an array of microorganisms such as bacteria, moulds, and yeasts, as well as having been reported to inhibit toxin production by micro-organisms $[8,9,13,17,18]$.

\subsection{Commercial use of trans-cinnamaldehyde}

trans-Cinnamaldehyde is Generally Recognized as Safe (GRAS) by the United States Food and Drug Administration (FDA), and Flavour and Extract Manufacturer's Association (FEMA), and has been granted A status (i.e. may be used in foodstuffs) by the Council of Europe [17]. On this basis, trans-Cinnamaldehyde can be viewed as a safe food and flavour additive, with a pleasant taste and odour, and has found many commercial food uses $[15,17]$. Cinnamon has been a useful spice since biblical times, when it was utilized as a perfume in rubbing oils [11]. Egyptians employed cinnamon as a fragrance for preserving bodies [11] and more recently, trans-cinnamaldehyde has been used agriculturally as a fungicide [19]. Cinnamaldehyde has also been incorporated into edible antimicrobial films, prepared from foodstuffs such as fruit and vegetables, and has inactivated foodborne pathogens either by direct contact or by vapours released from the films in closed containers [20]. These films have also been shown to reduce the presence of non-pathogenic spoilage organisms that impact food quality [17]. This correlates with a growing interest in natural antimicrobials that not only prevent the growth of foodborne pathogens and spoilage microorganisms, but can also enhance the flavour and quality of foods [21]. Thus, in light of trans-cinnamaldehyde being a safe additive that is already being added to foods to enhance flavour, related cinnamaldehyde derivatives have the potential to be cost-effective, food-compatible, broad-spectrum antimicrobial additives that could be used against an array of pathogenic micro-organisms [17], and hence have sparked the 
interest of researchers across the globe.

\subsection{Limitations of trans-cinnamaldehyde for commercial applications}

There have been some undesirable aspects reported for trans-cinnamaldehyde that has limited its commercial use. For one, the solubility of this compound in water is low at approximately $1.1 \mathrm{~g} / \mathrm{L}$ at $20^{\circ} \mathrm{C}$ [19]. It is also sensitive when exposed to light and air for prolonged periods [19]. In vivo, it is possible that trans-cinnamaldehyde decomposes to cinnamic acid by enzyme catalysis before it is able to elicit its antibacterial activity, hence could be considered unstable in blood [12]. Additionally, J. Visvalingham et al. [9] were the first to show that Escherichia coli (E. coli) O157:H7 can convert cinnamaldehyde to cinnamic alcohol using dehydrogenase/reductase enzymes [9]. Cinnamaldehyde is a known sensitizer in humans and the North American Contact Dermatitis Research group have reported that cinnamaldehyde is a frequent cause of allergic reactions as a constituent of perfumes and cosmetics [11]. In human dermatological studies, the No-ObservedAdverse-Effect-Level (NOAEL) for cinnamaldehyde sensitization has been set at $0.5 \%$ [11]. For this reason, the International Fragrance Research Association (IFRA) has limited its use to 0.05\% [11]. Thus, this highlights the need for research into cinnamaldehyde derivates that have lower sensitization effects, lower toxicity, but improved antibacterial activity to that of trans-cinnamaldehyde.

\section{General medicinal properties of cinnamaldehyde and its derivatives}

Extensive research has been carried out investigating the broad scope of medicinal applications associated with cinnamaldehyde and its natural and synthetic derivatives. A number of excellent reviews have been published with respect to the medicinal properties associated with trans-cinnamaldehyde itself (Fig. 1, structure 1) [12,17,19], as well as reviews on cinnamaldehyde derivatives and their associated medicinal properties including noteworthy examples by Chen et al. [22] and Shreaz et al. [11]. The following section will discuss a number of medicinal applications for which cinnamaldehyde and its derivatives have been studied. Other applications for trans-cinnamaldehyde including anti-mold, anti-diabetes, neuroprotective, and anti-oxidant functions, have all been discussed previously in the literature [22-24].

\subsection{Anticancer/antitumour activity}

One such medicinal application discussed in depth is the use of trans-cinnamaldehyde, as well as its derivatives, as potential anti-tumour and anti-cancer agents. Trans-Cinnamaldehyde has been shown to be active against a number of cancer cell lines, including A549 lung, SKOV-3 ovarian, and XF-498 central nerve system cell lines [25]. In addition, cinnamaldehyde has been reported to significantly inhibit NNK (4-(methylnitrosamino)-1-(3-pyridyl)-1-butanone) induced pulmonary carcinogenesis in vivo in rasH2 male mice [26]. Notably, trans-cinnamaldehyde exhibited comparable activity to anticancer agents such as cisplatin with respect to HeLa epithelioid cervix, SK-MEL-2 melanoma, and HCT-15 colon tumour cells [25]. With respect to its demonstrated ability to inhibit human hepatoma PLC/PRF/5 cell proliferation, cinnamaldehyde has also been shown to cause the cell cycle to arrest in the $\mathrm{S}$ phase and to induce apoptosis by activating pro-apoptotic Bcl-2 family proteins, namely Bax and Bid, as well as activating the MAPK (mitogen-activated protein kinases) signalling pathway [27].

A number of synthetic cinnamaldehyde derivatives including 2benzoyloxycinnamaldehyde, 4-hydroxycinnamaldehyde, 2-hydroxy-5fluorocinnamaldehyde, CB403 and a number of synthesized dimer analogues as well as naturally-occurring 2-hydroxycinnamaldehyde and 2-methoxycinnamaldheyde (Fig. 1, structure 2-7) have demonstrated anti-cancer properties against a range of cancer cell lines. These include human leukemic, oral carcinoma, prostate and colon cancer cell lines
[28-31], with their mechanisms of action having been investigated in some cases (Fig. 1, structure 8-11) [23,28-37]. Cabello et al. [38] investigated the effect of not only the naturally occurring trans-cinnamaldehyde and cinnamic acid, but also a range of synthetic cinnamaldehyde derivatives on melanoma cell proliferation, invasiveness, and tumour growth [38] and found that Michael acceptor ability was important for activity, as discussed later in section 3.0. A similar finding was observed in other bioactivity assays, including that conducted by Motohashi et al. [39] who have evaluated the structure-activity relationship of antimutagenic benzalacetone (Fig. 1, structure 12) and its related compounds, also discussed later in section 3.0 [39]. Jeong et al. [40] synthesized a range of cinnamaldehyde derivatives in order to identify their anti-tumour mechanism of action and characterised these compounds as cyclin dependent kinases (CDK) 4 inhibitors. Research in this area has placed a focus on cyclin D1-CDK4 complexes as there is growing evidence that its activity is vital for proliferation of many tumours [40]. Synthesized (E)-3-benzoyloxycinnamaldehyde was found to possess the greatest activity of those trans-cinnamaldehydes evaluated by Jeong et al. [40].

\subsection{Cardioprotection function}

The cardioprotection and related activity of cinnamaldehyde and its derivatives has also been studied. X.-Q Li et al. [41] assessed the therapeutic effects of cinnamaldehyde and five derivatives on viral myocarditis (VMC). Here, synthetic derivatives $\alpha$-bromo-4-methylcinnamaldehyde and $\alpha$-bromo-4-chlorocinnamaldehyde (Fig. 1, structure 13) showed considerable inhibition of CVB3 replication and CVB3-induced cardiac injury both in vitro and in vivo. These two derivatives showed improved anti-vital and anti-inflammatory activity, as well as lower toxicity relative to cinnamaldehyde. Song et al. [42] demonstrated that cinnamaldehyde exhibited cardioprotective effects against acute ischemic myocardial injury induced by isoproterenol in rats. The authors suggest that its anti-oxidative and anti-inflammatory properties, as well as its ability to elevate nitric oxide levels, might have contributed to its observed cardioprotective properties. Similar effects have been observed with respect to naturally occurring 2-methoxycinnamaldheyde (Fig. 1, structure 7) [43]. The vasodilatory properties of cinnamaldehyde have also been established and it has been indicated that such properties are attributable to cinnamaldehyde's ability to interfere with $\mathrm{Ca}^{2+}$ influx and release $[23,44]$.

\subsection{Cinnamaldehyde and derivatives as anti-inflammatory agents}

The potential of trans-cinnamaldehyde and its derivatives as antiinflammatory agents has also been reported. Nuclear factor (NF)- $\mathrm{kB}$ is a transcription factor that regulates the expression of inflammatory and immune genes. Reddy et al. [45] identified trans-cinnamaldehyde and naturally occurring 2-methoxycinnamaldehdye (Fig. 1, structure $1 \& 7$ ) as NF- $\mathrm{kB}$ inhibitors, which were shown not only to inhibit its transcriptional activity but also to inhibit its lipopolysaccharide (LPS)-induced DNA binding in a dose-dependent manner. Guo et al. [46] showed that cinnamaldehyde inhibits interleukin (IL)-1ß-induced prostglandin $\mathrm{E}_{2}\left(\mathrm{PGE}_{2}\right)$ production by inhibiting cyclooxygenase (COX)2 activity. This was demonstrated using cultured rat cerebral microvascular endothelial cells (RCMEC). Both IL-1 $\beta$ and $\mathrm{PGE}_{2}$ are associated with causing fevers. Liao et al. [47] investigated the anti-inflammatory effects of cinnamaldehyde and suggested that its mechanism of action may relate to its ability to inhibit the protein expression of inducible nitric oxide synthase (iNOS), in addition to increasing the activities of antioxidant enzymes catalase, superoxide dismutase, and glutathione peroxidase [47]. Kwon et al. [48] similarly demonstrated that synthetic 2-benzoyloxycinnamaldehyde (Fig. 1, structure 2) inhibited the LPSinduced NO production and iNOS expression, doing so without affecting cell proliferation or causing cytotoxicity. Its mode of action was identified as the inhibition of JNK activation and subsequent AP-1 
activation. Thus, 2-benzoyloxycinnamaldehyde has been suggested as a promising candidate for the treatment of inflammation-related disease [48]. Rao et al. [23] also discussed the evaluation of naturally-occurring 2'-hydroxycinnamaldehyde (Fig. 1, structure 6) as a potential antiinflammatory agent, by the inhibition of NO production via reducing the activation of NF-??B.

\subsection{Antifungal activity}

The antifungal properties of cinnamaldehyde and its derivatives is well established. Cinnamaldehyde and its derivatives have been have been screened against several pathogenic fungi and shown to exhibit antifungal activity against Aspergillus flavus [49,50], Aspergillus fumigatus and Trichophyton rubrum [51], Coriolus versicolor and Laetiporus sulphurous [52], Aspergillus ochraceus as well as its associated toxins [53,54], and Candida spp including some fluconazole-resistant strains [55,56]. Interestingly, cis-cinnamaldehyde, the geometrical isomer of trans-cinnamaldehyde, has also been shown to possess antifungal properties [57]. There are numerous reported investigations into cinnamaldehyde and its derivatives as antifungal agents, with Shreaz et al. [11] having published an excellent review on this topic in 2016. They note that cinnamaldehyde itself is interesting as a potential antifungal agent because, aside from the extensive antifungal activity it exhibits, it can potentially overcome some of the drawbacks of current antifungal chemotherapy. This is in light of its rapid and irreversible in vitro activity against several fluconazole-resistant Candida strains, with no associated toxicity being observed against $\mathrm{H} 9 \mathrm{c} 2$ cells and human RBCs [55,56]. They also affirm the potential of cinnamaldehyde derivatives as alternatives to current antifungal treatments, highlighting the significant activity of such cinnamaldehyde synthetic derivatives as 2(-bromo-cinnamaldehyde) (Fig. 1, structure 14), 2(-chloro-cinnamaldehyde), $\alpha$-methyl cinnamaldehyde, as well as a range of amino acid-based adducts of cinnamaldehyde [58], and naturally-occurring derivatives o-methoxy cinnamaldehyde (Fig. 1, structure 7) [59,60], coniferyl aldehyde and sinapaldehyde (Fig. 1, structures 15 \& 16) [56,61]. Interestingly, commercial cinnamon preparations containing trans-cinnamaldehyde and $o$-methoxycinnamaldehyde also gave relief to three out of five HIV patients with oral candidiasis [62].

\subsection{Thermogenic effects}

Studies by Jiang et al. [63] have indicated that cinnamaldehyde activates thermogenic responses in both mice and humans. This is evidenced by several results. For example, post-treatment with $400 \mu \mathrm{M}$ cinnamaldehyde resulted in the up regulation of thermogenic genes and activation of PKA signalling. This is significant as PKA activation is a large component of the classical pathway for the activation of thermogenesis in adipocytes. Cinnamaldehyde was also shown to activate metabolic responses. For example, after administration of $200 \mu \mathrm{M}$ cinnamaldehyde the authors observed the upregulation in expression of (i) lipolytic genes $\mathrm{Hsl}$ and $\mathrm{Atg}$, (ii) key regulators in fatty acid oxidation Cpt1b and Ppara, and (iii) the enzyme Pdk4 that increases lipid metabolism and has been reported to be attributed to major metabolic adaptations during white-to-beige conversion of human adipocytes. Not only were thermogenic and metabolic responses shown to be activated in mouse and human primary subcutaneous adipocytes in response to cinnamaldehyde, but the results of this study suggest that this is done in a cell-autonomous manner. This is important as it gives a plausible mechanistic explanation for the anti-obesity effects of cinnamaldehyde that has been observed in previous studies [64,65]. In addition, it further supports its potential metabolic benefits on humans, an important observation given the wide usage of cinnamaldehyde commercially, particularly with respect to the food industry where it is commonly used as a food additive [63].

Masamoto et al. [66] also found that cinnamaldehyde enhanced thermogenesis and inhibited heat diffusion. This was deduced on the basis that the administration of cinnamaldehyde $(50 \mathrm{mg} / \mathrm{kg}$ of body weight) to 7-week-old male mice of the C57BL/ 6 strain increased both colonic temperature (by approximately $\Delta+0.7^{\circ} \mathrm{C}$ after $240 \mathrm{~min}$ ) and intrascapular brown adipose tissue temperature (by approximately $\Delta+0.9^{\circ} \mathrm{C}$ after $240 \mathrm{~min}$ ). Throughout the 240 -min period, the control group changed by approximately $\Delta+0.1^{\circ} \mathrm{C}$ and $\Delta+0.05^{\circ} \mathrm{C}$, respectively. Exposure to cinnamaldehyde did not increase the tail-skin temperature, conversely it decreased the tail skin temperature but only by approximately $\Delta-0.175^{\circ} \mathrm{C}$ after $200-240 \mathrm{~min}$. The control group showed a slight increase by approximately $\Delta+0.175^{\circ} \mathrm{C}$ during this timeframe. Overall, the results of this study suggest that thermosensitive transient receptor potential channels (thermoTRPs) could play a role in controlling autonomic thermoregulation [66].

In a study by Iwasaki et al., [67] cinnamaldehyde was investigated for its ability to enhance adrenaline secretion as an indicator of energy metabolism and thermogenesis in rats. A number of results were collected as part of this investigation. For example, the intravenous administration of $10 \mathrm{mg} / \mathrm{kg}$ cinnamaldehyde to male Sprague-Dawley rats (7-8 weeks of age) increased the adrenaline secretion from the adrenal gland in a concentration-dependent manner. After approximately $2 \mathrm{~min}$, the adrenaline secretion increased to approximately $110 \mathrm{ng} / \mathrm{kg} /$ min relative to the vehicle control of approximately $20 \mathrm{ng} / \mathrm{kg} / \mathrm{min}$ at the same time point. Additionally, cinnamaldehyde at the same dose was observed to enhance the total adrenaline secretion for $20 \mathrm{~min}$ after sample injection, increasing this value to approximately $1250 \mathrm{ng} / \mathrm{kg}$ relative to the vehicle control of $250 \mathrm{ng} / \mathrm{kg}$. These results are significant, as the authors suggest that adrenaline secretion via the intake of a TRPA1 agonist, such as cinnamaldehyde, might be an explanation for diet-induced thermogenesis caused by such spices as cinnamon [67].

Michlig et al. [68] studied the effects of the ingestion of TRP channel agonists, including cinnamaldehyde, on metabolism and related processes through the stimulation of the sympathetic nervous system. This study was conducted on men, deemed to be in good health, between 20 and 50 years old with a weight greater than $60 \mathrm{~kg}$. The group hypothesized that the stimulation of such TRP pathways as TRPA1 could increase thermogenesis, promoting energy expenditure and consequently exhibit an anti-obesity effect. A number of results were obtained to investigate this hypothesis. One such result showed that a single administration of $350 \mathrm{ppm}$ cinnamaldehyde increased energy expenditure by approximately $3.6 \mathrm{kcal}$ over the course of the 90min experiment, as compared to the placebo. Additionally, it was shown that cinnamaldehyde and capsaicin, which has been widely studied for its thermogenic and metabolic effects, exhibited similar peripheral thermoregulation once ingested. Importantly, the dose of cinnamaldehyde was not judged to be sensorially 'too intense' by participants, as has been reported with respect to capsaicin. This led the authors to suggest that cinnamaldehyde may be more potent than capsaicin in terms of improving energy expenditure via thermogenic effects [68]. While thermogenesis induced by spices is a well-studied area of research, Pandit and Anilakumar [69] note that, prior to 2017 when they conducted their study, there had been no investigation as to whether the ingestion of spices that induce thermogenic mechanisms can improve cold endurance. They note that this could be an important application, given that potentially it could delay or prevent hypothermia. In this study, cinnamon extracts in a dose of $250 \mathrm{mg} / \mathrm{kg}$ for a 7-day period was administered to six male Albino Wistar rats. A number of results were obtained as part of this study. One such result was the recording of core body temperature before and after treatment, and after exposure of the rats to $4 \pm 1{ }^{\circ} \mathrm{C}$. After treatment with cinnamon extracts, a statistically significant improvement was observed relative to the control. With respect to the control, core body temperature fell by $10^{\circ} \mathrm{C}$ after treatment whereas after cinnamon extract ingestion, core body temperature fell by $5{ }^{\circ} \mathrm{C}$. On the basis of evidence in the literature, the group hypothesized that the observed effects may be due to cinnamaldehyde content in the cinnamon extract and as a result administered cinnamaldehyde alone to investigate this. However, 
endurance was not observed to improve when it was administered in a dose approximately equivalent to the cinnamaldehyde content of the cinnamon extract sample. For example, the core body temperature fell by approximately $7^{\circ} \mathrm{C}$ after treatment with cinnamaldehyde. Despite confirming the presence of cinnamaldehyde in the cinnamon extract by HPLC and MS analysis, the lack of improved endurance following administration of cinnamaldehyde indicated to the authors that the observed thermogenesis of cinnamon extract may be as a result of a synergistic action of the various components it contains in addition to cinnamaldehyde [69].

\section{Molecular mechanism: cinnamaldehyde as an electrophile}

Cinnamaldehyde has two electrophilic reactive sites, the $\beta$-carbon on the conjugated double bond and the carbon of the aldehyde carbonyl group [17]. A number of previous studies have related the bioactivity of cinnamaldehyde and its derivative to its potential Michael acceptor ability, i.e. nucleophilic attack at the $\beta$-carbon. For example, Cabello et al. [38] related the Michael acceptor ability of trans-cinnamaldehyde and a range of its derivatives to their ability to impair melanoma cell proliferation, viability, invasiveness, and NF- $\mathrm{\kappa B}$ transcriptional activity. They observed that trans-cinnamaldehyde, but not structurally similar compounds devoid of Michael acceptor ability such as cinnamyl alcohol (Fig. 1, structure 17), possessed this ability [38]. A related example can be found in the findings of Motohashi et al. [39] who conducted a structure-activity relationship study using antimutagenic benzalacetone (Fig. 1, structure 12), as well as a number of cinnamaldehydes and cinnamic acids. This group similarly found that the presence of the unsaturated bonded-carbonyl system is necessary for biological activity, namely the inhibition of mutagenesis activity [39].

G. Brackman et al. [70] conducted a structure-activity relationship of cinnamaldehyde analogues as AI (autoinducer)-2 based quorum sensing inhibitors in Vibrio spp. It was suggested that those analogues containing an $\alpha, \beta$-unsaturated acyl group with potential to act as Michael acceptors (for example 2-nitrocinnamaldehyde 18 3,4-dichlorocinnamaldehyde 19 and cinnamaldehyde 1 , were found to possess greater activity with respect to the inhibition of bioluminescence of $V$. harveyi BB170. However, analogues that did not possess an $\alpha, \beta$-unsaturated acyl group, such as 3-phenylpropionaldehyde 20, did not result in a significant inhibition of the bioluminescence signal and is discussed in more detail in section 4.3.2. The group proposed that these effects may be as a result of a Michael-addition reaction in the mechanism of action, allowing trans-cinnamaldehyde and its analogues to act as LuxR-ligands. This could yield a modified protein that likely resulted in the reduced ability to bind to DNA. The reduced DNA binding was observed experimentally and measured in terms of $K_{d}$ values, see section 4.3.2.

More recent studies have however indicated, perhaps surprisingly, that it is the carbonyl carbon that is more significant in terms of reactivity than the $\beta$-carbon. For example, Sadofsky et al. [71] investigated the mechanism leading to the activation of TRPA1 (transient receptor potential ankyrin 1), a cation channel that plays an important role in the sensation of pain, inflammation, and coughs. Specifically, this group investigated the mechanism by which TRPA1 of cysteine residues is activated. This was done through the examination of a series of $\alpha, \beta$-unsaturated carbonyl compounds that are capable of undergoing either direct and/or conjugate addition processes. The data presented indicates that TRPA1 is activated by direct addition of the thiol group of cysteines to the agonist carbonyl carbon. This was assessed by analysing a range of compounds, for example, cinnamic acid, acrylic acid, and acrylamide, all of which were chosen as they contain both a carbonyl carbon and an unsaturated $\beta$-carbon but are weakly electrophilic at the carbonyl carbon. These compounds were observed to cause little or no TRPA1 activation in concentrations up to $300 \mu \mathrm{M}$. In contrast those compounds such as acrolein and cinnamaldehyde, which can react via either conjugate addition at the $\beta$-carbon or reversible direct addition at the carbonyl carbon, caused TRPA1 activation in a concentration dependent manner. With respect to these reactive aldehydes, the authors indicate that it is the reversible direct addition that is responsible for the channel activation, which would explain why TRPA1 agonists such as cinnamaldehyde acted in a manner compatible with reversible, competitive agonism. Similarly, both hydrocinnamic acid NHS ester and propionic acid NHS ester, which are only capable of direct addition, activated TRPA1 expressed in HEK293 cells [71].

Autelitano et al. [72] investigated the reaction of cinnamaldehyde and cinnam(o)yl derivatives with thiols. Here dodecanethiol was employed as a model of simple thiols, with cysteamine utilized as a model of reactive protein thiols in an NMR assay as developed by Avonto et al. [73]. This study was carried out to probe the selective reactivity of cinnamaldehyde at both the carbonyl carbon and the $\beta$-carbon. Other compounds were also investigated in this study, for example cinnamyl ketones and oximes, with most exhibiting no reactivity. Cinnamaldehyde, when reacted with cysteamine, afforded a mixture of a thiazoline derivative and compounds of multiple addition at both the carbonyl and $\beta$-carbon. The reaction with dodecanethiol gave a bis-dithioacetal via direct addition, but no reaction occurred between dodecanethiol and the saturated dihydrocinnamaldehyde (Fig. 1, structure 20). A possible explanation was given in that for cinnamaldehyde (vs dihydrocinnamaldehyde) conjugation to a phenyl reduces the hardness of the carbonyl to the point of making it possible for a weak and soft nucleophile like sulfur to attack it without any previous catalysis. These surprising results, suggest that cinnamaldehyde can trap simple thiols via direct addition, and can also trap cysteamine type thiols but only after imine formation with the amino motif [72].

\section{Antibacterial activity of cinnamaldehyde and its derivatives}

trans-Cinnamaldehyde has known antibacterial properties that have been established across an array of Gram-positive and -negative bacteria, including E. coli [6,10,12,23,74] Bacillus subtilis (B. subtilis) [10,12,74], Staphylococcus spp. [12,17,23,74], Listeria spp. and Salmonella spp. [6,10,12,17,74], Lactobacillus sakei [74], Campylobacter jejuni [6,75], Vibrio spp. [3,10,12], Pseudomonas spp. [3,10,12,23], Porphyromonas gingivalis [12], Streptococcus pyogenes [3], and Cronobacter sakazakii $[12,17]$.

Some recent research has utilized trans-cinnamaldehyde as a hit compound, from which a range of derivatives have been synthesized and tested for their antibacterial activity. The following section highlights publications in which trans-cinnamaldehyde and derivatives have been investigated for their general antibacterial activity without reporting on a mechanism of action. One such case is that of Wei et al. [58], who developed nine Schiff base cinnamaldehyde compounds and tested them, along with cinnamaldehyde, against B. subtilis and E. coli. The antimicrobial activity of the Schiff base adducts were very near or higher than cinnamaldehyde. At the same molar concentration potassium (E)-N-[((E)-3-phenyl-1-ethenyl)methylene]glycinate (Fig. 2, structure 21), formed by the reaction of potassium glycinate with cinnamaldehyde, was found to be more active than cinnamaldehyde. The inhibition zone diameters of 21, at a concentration of $600 \mathrm{mg} / \mathrm{L}$ ( $2.64 \mathrm{mmol} / \mathrm{L})$, for $E$. coli and B. subtilis were $11.8 \mathrm{~mm}$ and $12.6 \mathrm{~mm}$ respectively. The inhibition zone diameters of cinnamaldehyde, for the same bacteria at a concentration of $400 \mathrm{mg} / \mathrm{L}(3.0 \mathrm{mmol} / \mathrm{L})$, were $10.3 \mathrm{~mm}$ and $11.0 \mathrm{~mm}$ respectively. It is also noteworthy that $\mathbf{2 1}$ exhibited practically no associated toxicity according to the criteria of acute toxic classifications, where it was determined that the oral acute toxicity was more than $2500 \mathrm{mg} / \mathrm{kg}$ body weight in mice [58]. Following on from this work, Wang et al. [76] synthesized twenty four Schiff base cinnamaldehyde analogues using cinnamaldehyde, 4chlorocinnamaldehyde, and 4-methoxycinnamaldehyde as the cinnamaldehyde component. The three cinnamaldehydes were combined with one of eight amino acids to generate the corresponding Schiff base. Results indicate that all compounds inhibited the growth of the two 


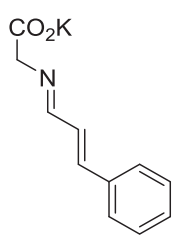

$21^{b}$

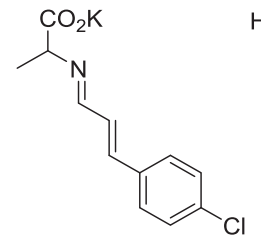

$22^{b}$

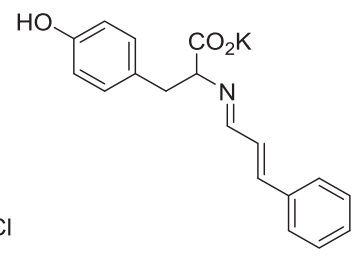

$23^{b}$

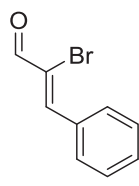

$24^{\mathrm{b}}$

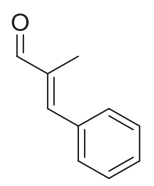

$25^{a}$

Fig. 2. Cinnamaldehyde derivatives shown to possess general antibacterial activity. [58,76,78].

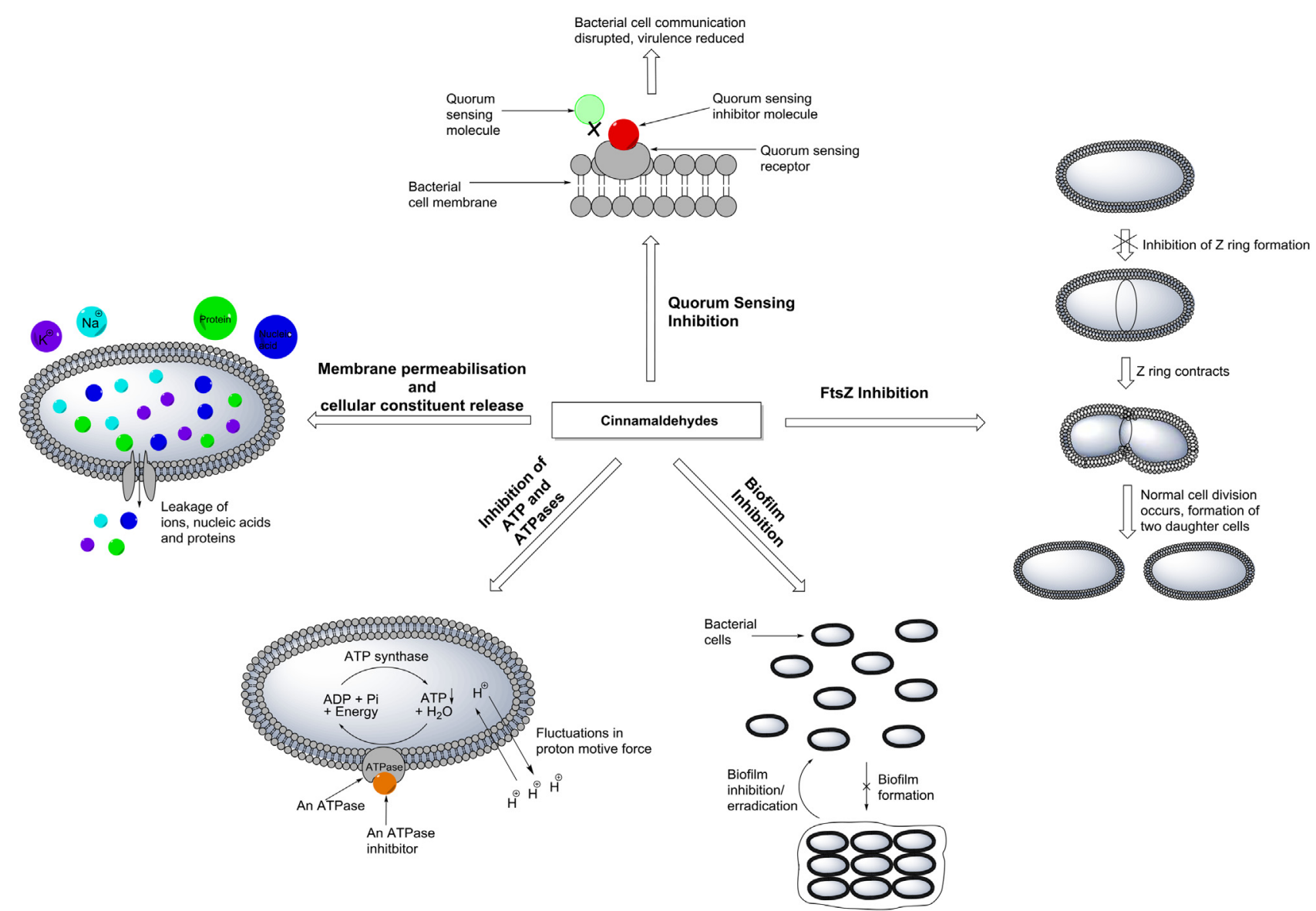

Fig. 3. Graphical depiction of antibacterial mechanisms of action exhibited by cinnamaldehydes.

bacteria Staphylococcus aureus (S. aureus) and E. coli. 22 and 23 (Fig. 2) exhibited the best antibacterial activity. 23 had the highest associated inhibition zone diameter of $31.3 \mathrm{~mm}$ against $E$. coli, compared to that of cinnamon oil of $29.5 \mathrm{~mm}$ and that of the common antibiotic ciprofloxacin of $24.3 \mathrm{~mm} . \mathbf{2 2}$ had the highest associated inhibition zone diameter of $33.7 \mathrm{~mm}$ against $S$. aureus, compared to that of cinnamon oil of $10.5 \mathrm{~mm}$ and that of ciprofloxacin of $21.0 \mathrm{~mm}$. These results were all generated with test concentrations of $0.25 \mathrm{~mol} / \mathrm{L}$. Two mold fungi were also examined in this study and it was found that they were more sensitive to the cinnamaldehyde derivatives than the two test bacteria [76].

In 2016, Liu et al. [77] synthesized Schiff base cinnamaldehyde metal complexes using $\gamma$-aminobutyric acid (GA) and cinnamaldehyde, as well as copper $\left(\mathrm{Cu}^{2+}\right)$ and zinc $\left(\mathrm{Zn}^{2+}\right)$. The Schiff base-metal complexes were evaluated for their inhibitory effect against $S$. aureus and $E$. coli. The cinnamaldehyde-GA Schiff base was shown to possess better antibacterial activity against $S$. aureus than $E$. coli, as assessed by MBC (minimal bactericidal concentration) values. An MBC of $46 \mu \mathrm{g} / \mathrm{mL}$ against $S$. aureus was reported and compared to an $\mathrm{MBC}$ of $375 \mu \mathrm{g} / \mathrm{mL}$ against $E$. coli. For $S$. aureus, both metal complexes of cinnamaldehydeGA were shown to enhance the antimicrobial activity compared to the
cinnamaldehyde-GA Schiff base alone, where the MBC of the cinnamaldehyde-GA- $\mathrm{Cu}^{2+}$ complex was found to be $11 \mu \mathrm{g} / \mathrm{mL}$ and that of the cinnamaldehyde-GA-Zn ${ }^{2+}$ complex was found to be $23 \mu \mathrm{g} / \mathrm{mL}$. However, only the cinnamaldehyde-GA- $\mathrm{Cu}^{2+}$ complex improved the activity of the original Schiff base with respect to $E$. coli, whose MBC value was determined as $187 \mu \mathrm{g} / \mathrm{mL}$. The cinnamaldehyde-GA- $\mathrm{Zn}^{2+}$ complex showed the same activity as original Schiff base, with a MBC value of $375 \mu \mathrm{g} / \mathrm{mL}$. Thus, while this study showed that the cinnamaldehyde-GA Schiff base possessed good antibacterial effects, its activity can be enhanced by complexing with $\mathrm{Cu}^{2+}$ and also $\mathrm{Zn}^{2+}$ in the case of $S$. aureus [77].

Shen et al. [78] investigated the ability of cinnamaldehyde and its derivatives to eradicate persisters in E. coli. Persisters lead to recurring infections and relapse after treatment and are widely occurring throughout bacteria as well as fungi and parasites. $\alpha$-Bromocinnamaldehyde (Fig. 2, structure 24) was shown to exhibit the best activity of those compounds evaluated, having an associated killing rate of $100 \%$ in concentrations up to $400 \mu \mathrm{g} / \mathrm{mL}$, compared with cinnamaldehyde having a similar killing rate of $99.8 \%$ across the same concentrations. Less than $1 \%$ of cells survived after administration of $\alpha$ bromocinnamaldehyde at a concentration of $100 \mu \mathrm{g} / \mathrm{mL}$, and at a 
concentration of $400 \mu \mathrm{g} / \mathrm{mL} \alpha$-bromocinnamaldehyde was able to eradicate all $E$. coli cells in the exponential phase as well as cells in the stationary phase. Cells in the stationary phase are often resistant to traditional antibiotic treatment. Interestingly, $\alpha$-methylcinnamaldehyde (Fig. 2, structure 25) was shown not to display any bactericidal activity at any concentration examined, while phenylpropyl aldehyde (Fig. 1, structure 20), without an $\alpha, \beta$-unsaturated bond, exerted bactericidal activity with an associated killing rate of $92.1 \%$. The group also found that $\alpha$-bromocinnamaldehyde displayed a mechanism of action that is different from some common antibiotics. For example, results from this study indicate that the mechanism of action for $\alpha$ bromocinnamaldehyde is independent of Reactive Oxygen Species (ROS) [78].

While there are many examples in the literature of studies exploring the antibacterial activity of trans-cinnamaldehyde, there are fewer where the antibacterial activity of cinnamaldehyde derivatives along with their mechanism of action have been studied. In the following sections of this review, we would like to highlight publications that offer significant insight into the mechanism of action of trans-cinnamaldehydes and have grouped the selected publications into the different proposed mechanisms of action (Fig. 3). We do recommend that the reader consults the referenced articles in order to fully explore each citation.

\subsection{FtsZ inhibition by cinnamaldehydes}

Filamentous temperature-sensitive protein Z (FtsZ) is a key cytoplasmic protein in the cell division process [79-83]. FtsZ was discovered in the 1970s [80] and is conserved in virtually all bacterial species [79-82]. For example, FtsZ is present in the cells walls of such bacteria as E. coli and Bacillus subtilis [81], as well as in archaea [79,82], and chloroplasts [79]. In 1991, it was found that FtsZ assembled into a ring structure, termed a $Z$-ring, at the center of the cell [84] and that this Z-ring dynamic structure is essential in facilitating cytokinesis and recruiting other cell division proteins that bind to the Z-ring sequentially. Subsequently, the $\mathrm{Z}$ ring contracts leading to the closure of the septum, which coincides with the formation of two daughter cells $[79,80,83,84]$. FtsZ is an important GTPase and is considered to be a homolog of eukaryotic tubulin $[80,82,83]$. However, it does possess certain structural features that are different than tubulin; notably greater than $80 \%$ of the FtsZ primary sequence varies to that of tubulin [84]. Additionally, FtsZ subunits are indistinguishable, whereas eukaryotic microtubules are made up of two distinct tubulin subunit types ( $\alpha$ and $\beta$ ) [84]. The presence of such differences between FtsZ and tubulin is important, and supports the hypothesis that antibacterial agents could potentially be developed that selectively target FtsZ over tubulin in vivo. Consequentially, this would lower the risk of accompanying adverse effects upon administration [84]. Such selective targeting, along with its fundamental role in the bacterial cell division process and presence in such a variety of bacteria, makes FtsZ an attractive target for researchers involved in the development of novel antibacterial agents $[79,81,82]$. trans-Cinnamaldehyde, as well as some of its derivatives, have been shown to inhibit the cell division process by binding to FtsZ.

\subsubsection{FtsZ inhibition by trans-cinnamaldehyde}

Domadia et al. [85] made valuable contributions to the understanding of how trans-cinnamaldehyde inhibits FtsZ with a number of important observations. The group noted that even at doses exceeding its MIC and MBC values, where the MIC was found to be $1 \mathrm{~g} / \mathrm{L}$ and $0.5 \mathrm{~g} / \mathrm{L}$ respectively for $E$. coli and $B$. subtilis and the MBC was $1 \mathrm{~g} / \mathrm{L}$ for both strains, that trans-cinnamaldehyde did not possess any hemolytic activity toward human eukaryotic cells. The group also analyzed the effect of trans-cinnamaldehyde on FtsZ polymerization and GTPase activity in $E$. coli and saw that both were strongly inhibited. Here transcinnamaldehyde exhibited half-maximal inhibitory concentration $\left(\mathrm{IC}_{50}\right.$ ) values of $6.86 \pm 2.2 \mu \mathrm{M}$ and $5.81 \pm 2.2 \mu \mathrm{M}$ respectively. A nearly linear relationship was observed between antibacterial activity (indicated by the MIC for E. coli) and the FtsZ inhibition $\mathrm{IC}_{50}$ for E. coli, thus suggesting that FtsZ could be a selective target for trans-cinnamaldehyde. This was supported by the results obtained using isothermal titration calorimetry in the same study, which revealed that the binding of trans-cinnamaldehyde to FtsZ is driven by favourable enthalpic interaction, where $\Delta \mathrm{H}$ was found to be negative and a negative binding free energy was observed. An exothermic and thermodynamically driven FtsZ-cinnamaldehyde interaction was also shown by this method and an association constant of $1.0 \pm 0.2 \mathrm{M}^{-1}$ was found [85]. This group also showed that trans-cinnamaldehyde inhibited the bundling of FtsZ protofilaments in a dose-dependent manner in vitro. In the presence of $100 \mu \mathrm{M}$ trans-cinnamaldehyde, polymerization was almost completely inhibited. In addition, confocal imaging showed that $100 \mu \mathrm{M}$ trans-cinnamaldehyde disturbs Z-ring morphology in vivo, causing a reduction of Z-rings from $85.7 \%$ in the untreated control to $58 \%$ after treatment, as well as a reduction in the frequency of Z-rings per unit cell length of $E$. coli from 5.00 in the control to 2.88 after exposure [85].

Additionally, Domadia et al. [85] conducted analysis of the binding site of cinnamaldehyde in FtsZ using saturation transfer difference (STD)-NMR spectroscopy and in silico docking techniques. The study indicated that cinnamaldehyde binds to the T7 loop in the C-terminal region of a FtsZ monomer. This binding induces a conformation change that inhibits GTP-dependent FtsZ polymerization by blocking optimal contact with the GTP-binding T1-T6 loop in the neighbouring monomer. It was also shown using STD-NMR spectroscopy that it is the $\mathrm{H} 2$ and $\mathrm{H} 3$ protons of the conjugated alkene of cinnamaldehyde that are in close contact with FtsZ protons in its binding pocket. At that time, cinnamaldehyde was the only molecule known to target the T7 loop in FtsZ [85], although since then other molecules have been implicated as targeting the T7 loop directly or as binding in close proximity to the T7 loop. Such compounds include coumarins, such as scopoletin [80,81,86], 2,4-disubstituted benzimidazoles, such as BT-Benzo-29 [81], benzamide derivatives, such as PC190723 [86], and cathelin-related antimicrobial peptide (CRAMP) [80,81,86] (Fig. 4, structure 26-28). Domadia et al. [85] note that cinnamaldehyde may represent both a hit compound for the subsequent design of more stable and more potent FtsZ inhibitors, as well as a vital tool for understanding the regulatory role of FtsZ in cell division [85]. To the best of our knowledge, the work of Domadia et al. is the only experimental report describing the FtsZ inhibitory activity of cinnamaldehyde. Nazzaro et al. [10] reported that cinnamaldehyde exhibited inhibitory activity on cell separation of Bacillus cereus [10], referencing the work of Kwon et al. [13], but did not include results indicating the inhibition of FtsZ by cinnamaldehyde. As such, while the reported inhibition of cell separation may be as a result of FtsZ inhibition, it was not discussed as part of their study. The seminal work of Domadia et al. [85] remains an important contribution to this field.

\subsubsection{FtsZ inhibition by cinnamaldehyde derivatives}

In 2015, Li et al. [87] designed and synthesized a novel library of trans-cinnamaldehyde derivatives and tested them for their in vitro antibacterial activity against nine pathogen strains, including Grampositive and Gram-negative bacteria. The trans-cinnamaldehydes studied included (E)-3-(4-fluorophenyl)-1-(2-methyl-1H-benzo[d]imidazol-1-yl)prop-2-en-1-one (Fig. 4, structure 29), (E)-3-(4-chlorophenyl)-1-(2-methyl-1H-benzo[d]imidazol-1-yl)prop-2-en-1-one (Fig. 4, structure 30), and (E)-3-(2,4-dichlorophenyl)-1-(2-methyl-1Hbenzo[d]imidazol-1-yl)prop-2-en-1-one (Fig. 4, structure 31). These three examples displayed good antimicrobial activity and were evaluated by carrying out light scattering and GTPase assays in order to further validate the FtsZ targeted mechanism. In the light scattering assay, all the tested compounds displayed an obvious inhibition on FtsZ polymerization in a dose-dependent manner. The intensity of light 
<smiles>COc1cc2ccc(=O)oc2cc1O</smiles>

$26^{b}$

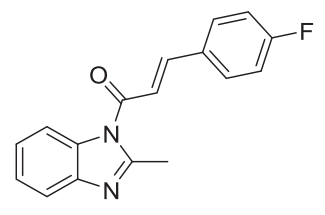

$29^{b}$
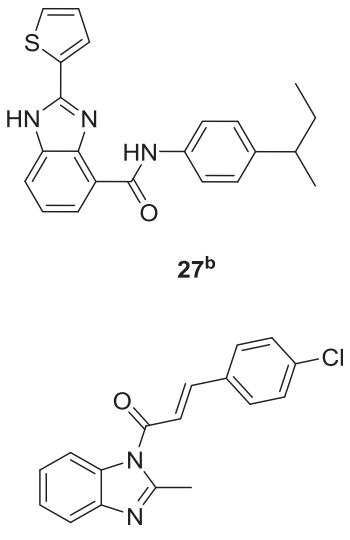

$30^{\mathrm{b}}$

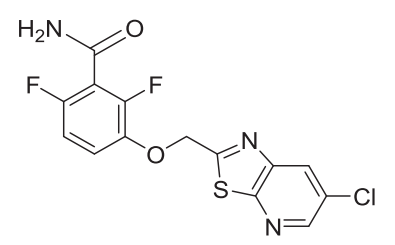

$28^{b}$

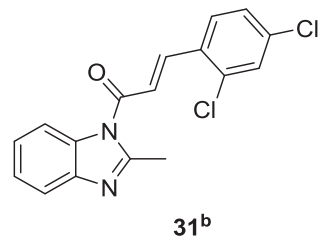

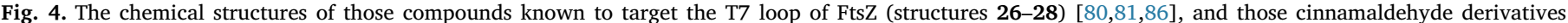
evaluated for their FtsZ inhibitory ability (structures 29-31) [87].

scattering for the E. coli ATCC 25922 untreated control was measured as 3000 by the end of the experiment at $2000 \mathrm{~s}$, which was reduced to 1000 at the $2000 \mathrm{~s}$ timepoint after administration of $120 \mu \mathrm{g} / \mathrm{mL} 29$ and to 1500 after administration of $120 \mu \mathrm{g} / \mathrm{mL}$ of $\mathbf{3 0}$ and $\mathbf{3 1}$ (at the same timepoint). 31 was the most active derivative tested and at a lowest concentration of $30 \mathrm{mg} / \mathrm{mL}$ reduced the intensity of light scattering intensity of $E$. coli ATCC 25922 to approximately 1750.

Li et al. [87] also described, in the same publication, the use of a GTPase assay, where the library of cinnamaldehyde derivatives tested tested exhibited a dose-dependent effect on the GTPase activity of FtsZ. Again compound 10 exhibited the best activity of those derivatives examined, showing $50 \%$ inhibition of the GTPase activity of $E$. coli ATCC 25922 at the lowest concentration studied of $30 \mathrm{mg} / \mathrm{mL}$. The inhibition of GTPase activity resulted a loss of stability for the FtsZ polymer, leading to abnormal bacterial cell division and then to cell death. The results suggested that the three compounds exhibiting the best antimicrobial activity are worth considering for further investigation as potent FtsZ-targeted antibacterial agents. Additionally, these compounds exhibited promising antibacterial activity against $S$. aureus ATCC25923, where for example, 31 was found to elicit a minimum inhibitory concentration of $4 \mu \mathrm{g} / \mathrm{mL}$ [87].

\subsection{Biofilm inhibition by cinnamaldehydes}

Biofilms are clusters of surface-associated microorganisms that are surrounded by a self-produced extracellular polymeric matrix [88]. A large body of research has been carried out in recent years examining the inhibition of biofilm formation as a potential mode of action for antibiotic agents. In the United States alone, an estimated $80 \%$ of hospital-acquired infections are caused by bacterial biofilms, which lead to $60,000-90,000$ deaths annually and amounts to an economic burden of \$17-\$29 billion each year [89]. In addition, according to the National Institutes of Health, up to $80 \%$ of bacterial infections that occur in humans involve biofilm-associated microorganisms [90]. Those bacteria associated with biofilm production are shown to be more resistant to both host defenses and antibiotic treatments, thus resulting in persistent and potentially less curable infections [90]. As such, microbial biofilms present a major challenge in both health and industrial settings [12], with an immediate need for novel strategies to treat these biofilm-associated infections [88]. The ability to target the biofilms associated with bacteria could provide a more specific treatment than traditional antibiotics, for example if biological effects specifically target the biofilm microenvironment. This would result in the degradation of the matrix, resulting in the eradication of associated pathogens with precision and therefore minimal cytotoxicity to surrounding tissues [91]. trans-Cinnamaldehyde itself has been the subject of many studies in this area and investigations of its antibiofilm properties have been conducted across a range of bacteria. There have been fewer biofilm inhibition studies involving derivatives of trans-cinnamaldehyde.

\subsubsection{Antibiofilm activity of trans-cinnamaldehyde against E. coli}

The inhibitory action of trans-cinnamaldehyde on biofilm formation has been reported across a number of different strains of $E$. coli, including uropathogenic E. coli [92,93], E. coli ATCC 33456 [94], and enterohemorrhagic E. coli O157: H7 (EHEC) [95]. In some cases, transcinnamaldehyde has even been shown to eradicate already established biofilms on different surfaces such as polystyrene and latex [93], giving rise to its potential application in clinical settings such as on catheters [92]. It has been shown that by increasing the concentration of cinnamaldehyde, the specific biofilm formation observed was reduced (for example, the specific biofilm formation was reduced by approximately $46 \%$ relative to that of the control after administration of $2.01 \mathrm{mM}$ cinnamaldehyde), as well as the specific cell adhesion (which was reduced by approximately $50 \%$ relative to that of the control after administration of $2.12 \mathrm{mM}$ cinnamaldehyde) [94]. Transcriptional analysis showed that cinnamon bark oil, of which cinnamaldehyde is a major component, down-regulated curli genes and Shiga-like toxin gene stx2 in EHEC at a concentration of $0.01 \% \mathrm{v} / \mathrm{v}$ [95]. It has also been shown to restrict the swimming motility of some $E$. coli strains by up to $60 \%$ when cells were exposed to cinnamaldehyde at a concentration of $2.17 \mathrm{mM}$ [94], and importantly did not exhibit any toxic effect on bladder epithelial cells at $1 \%, 1.25 \%$ or $1.5 \%$ concentrations [93]. It has been suggested that the aldehyde functional group in trans-cinnamaldehyde contributes to its antibiofilm activity [92]. This was deduced by Kot et al. [92] on the basis that trans-cinnamaldehyde was the only compound of the three plant-derived molecules evaluated capable of completely eliminating the biofilm of uropathogenic E. coli TransCinnamaldehyde was found to be the only compound that possessed an aldehyde functional group, the other two chemicals were carboxylic acids [92]. Across these studies it can be said that cinnamaldehyde may potentially be a safe, effective antibiofilm agent that could be used to prevent and inactivate E. coli-biofilm related infections. Additionally, the fabrication of materials such as PLGA (poly(lactic-co-glycolic acid)) coated with cinnamaldehyde or cinnamon bark oil was also shown to be effective at inhibiting EHEC biofilm formation at a concentration of $0.25 \%$, as visualized by confocal laser microscopy [95]. This shows the potential of not just cinnamaldehyde itself in this area but also other formulations of which this compound is a main constituent.

4.2.2. Antibiofilm activity of trans-cinnamaldehyde against $S$. aureus The cinnamaldehyde inhibition of several clinical strains of 
methicillin-resistant Staphylococcus aureus (MRSA) biofilms [88,96], SC-01 (an oxacillin- and methicillin-resistant clinical isolate of $S$. aureus) and its biofilms [97], as well as the biofilms of various isolates of $S$. aureus recovered from cases of subclinical bovine mastitis [98], has been reported. The work presented by Kavaunagh and Ribbeck [97] is perhaps particularly noteworthy as it was the first study to examine the effect of essential oils on the SC-01 strain. Here they showed that cassia oil, of which cinnamaldehyde is a major component, inhibited biofilm formation of this strain, with a minimal biofilm eradication concentration determined as approximately $0.5 \% \mathrm{v} / \mathrm{v}$ [84]. This level of activity makes it more active against the SC-01 strain than the commonly used antibiotic treatments oxacillin- and methicillin [97]. transCinnamaldehyde has not only been reported to inhibit the biofilm mass of $S$. aureus by up to $82.4 \%$ after a $48 \mathrm{~h}$ incubation period, depending on the strain, it can also reduce the metabolic activity of associated biofilms by $76.7-85.5 \%$ and $79.3-86 \%$ after $24 \mathrm{~h}$ and $48 \mathrm{~h}$ of treatment (using $0.1 \% \mathrm{v} / \mathrm{v}$ trans-cinnamaldehyde in all cases) [96]. Additionally, it was shown using real-time PCR that there was a notable decrease in sarA expression, sarA being a positive regulator of biofilm-associated protein, after exposure to trans-cinnamaldehyde. In some cases this was substantial, such as that observed for the JB-03 clinical strain where a 140 -fold reduction in the expression of sarA was observed after treatment with $0.0625 \%(\mathrm{v} / \mathrm{v})$ cinnamaldehyde [88]. These results collectively indicate the potential of cinnamaldehyde in the treatment of MRSA biofilm-related infections. Budri et al. [98] suggested that upon further development, an attractive application for cinnamaldehyde could materialize where it is employed as an alternative to sanitizing spray for use in the food processing industry. The Budri group reported that biofilms on two different surfaces, polystyrene and stainless steel, were reduced by $69.6 \%$ and $44.9 \%$ respectively after treatment with a concentration of $0.106 \mathrm{mg} / \mathrm{mL}$ cinnamaldehyde [98].

\subsubsection{Antibiofilm activity of trans-cinnamaldehyde against Pseudomonas} spp.

trans-Cinnamaldehyde has also been investigated with respect to its effect on biofilms associated with Pseudomonas spp. For example, Kavanaugh and Ribbeck [97] showed that cinnamaldehyde was effective in eradicating Pseudomonas aeruginosa $\left(\mathrm{PAO}_{1}\right)$ biofilms, exhibiting a minimal biofilm eradication concentration of $0.2 \% \mathrm{v} / \mathrm{v}$. This group also reported that cinnamaldehyde was as effective as cassia oil which generated the same minimal biofilm eradication concentration [97]. This is in agreement with the work of Kim et al. [95], who made the same observation regarding the antibiofilm activity against $\mathrm{PAO}_{1}$ of cinnamon bark oil, whose main constituent is also cinnamaldehyde. Here, cinnamon bark oil was shown to inhibit $\mathrm{PAO}_{1}$ biofilms by $96 \%$ at a concentration of $0.05 \% \mathrm{v} / \mathrm{v}$, with cinnamaldehyde showing similar activity at the same concentration. Additionally, this group found that the swarming motility of $P$. aeruginosa was almost abolished by the administration of $0.005 \% \mathrm{v} / \mathrm{v}$ cinnamaldehyde and $0.005 \% \mathrm{v} / \mathrm{v}$ cinnamon bark oil, as visualized using motility agar and compared to an untreated control [95]. The hemolytic activity of $P$. aeruginosa was also reduced by exposure to both cinnamon bark oil and cinnamaldehyde. The effect was more pronounced in the case of cinnamon bark oil, which at $0.02 \% \mathrm{v} / \mathrm{v}$ reduced hemolytic activity by more than $50 \%$, while cinnamaldehyde at the same concentration reduced this by approximately $40 \%$. The production of PQS (Pseudomonas quinolone signal, a quorum sensing molecule) was also inhibited by approximately $60 \%$ after treatment with cinnamon bark oil at $0.02 \% \mathrm{v} / \mathrm{v}$ and by approximately $30 \%$ after treatment with cinnamaldehyde at the same concentration [95].

Niu et al. [94] found that the specific biofilm formation by $\mathrm{PAO}_{1}$ decreased at cinnamaldehyde concentrations lower than $2 \mathrm{mM}$, but increased at cinnamaldehyde concentrations greater than $2 \mathrm{mM}$. This behavior was reasoned by the authors in terms of the activation of a stress-induced response leading to increased crystal violet (CV) staining, which is a colorimetric method that is widely used to measure biofilm formation, thus leading to the observed increase in specific biofilm formation. This group additionally found that $P$. putida KT2440 biofilms were reduced on increasing cinnamaldehyde concentration (for example, its specific biofilm formation was reduced by more than $80 \%$ at the highest concentration administered of $3 \mathrm{mM}$ cinnamaldehyde, relative to the control). However, the specific biofilm formation of $P$. fluorescens pSMC21 was observed not to be significantly inhibited at any concentration of cinnamaldehyde administered [94]. Li et al. [99] observed a clear inhibitory activity of cinnamaldehyde against $P$. fluorescens ATCC 13525 biofilms, with a decrease of approximately $35.74 \%$ being recorded after treatment with $0.025 \mu \mathrm{L} / \mathrm{mL}$ cinnamaldehyde. Further decreases were observed at higher concentrations of this compound, where the maximum biofilm inhibition rate recorded was $54.48 \%$ with the administration of $0.1 \mu \mathrm{L} / \mathrm{mL}$ cinnamaldehyde [99].

\subsubsection{Antibiofilm activity of trans-cinnamaldehyde against Crotobacter sakazakii}

The antibiofilm activity of trans-cinnamaldehyde has been investigated across a range of other bacteria, including Crotobacter sakazakii [100]. Here, Amalaradjou and Venkitanarayanan found that the inhibitory effect of trans-cinnamaldehyde on $C$. sakazakii biofilm formation significantly increased in a concentration dependent manner. For example, at $24^{\circ} \mathrm{C} 750 \mu \mathrm{M}$ trans-cinnamaldehyde reduced biofilm associated $C$. sakazakii counts on microtiter plates to approximately $2.40 \log$ CFU after a 96-h incubation period. This was in comparison with samples treated with $560 \mu \mathrm{M}$ trans-cinnamaldehyde, which contained more than $4.0 \log$ CFU by the end of the same incubation period. This inhibitory effect was also demonstrated on other surfaces such as enteral feeding tubes and stainless steel. This group also showed that trans-cinnamaldehyde was capable of inactivating fully formed $C$. sakazakii biofilms on many abiotic surfaces [100]. For example, a study using feeding tubes showed a reduction in biofilm-associated population from approximately $5 \log \mathrm{CFU} /$ piece to less than $1.5 \log \mathrm{CFU} /$ piece on treatment with $38 \mathrm{mM}$ trans-cinnamaldehyde. They also found, using reverse transcription quantitative PCR, that trans-cinnamaldehyde was able to significantly downregulate the expression of genes that were linked to biofilm formation, especially bcsA and LuxR, which were downregulated 71.43 fold and 20.83 fold respectively after exposure to $750 \mu \mathrm{M}$ trans-cinnamaldehyde [100]. Albano et al. [101] found that Staphylococcus epidermis biofilms on polystyrene microtiter plates were reduced by $74 \%, 84 \%$, and $89 \%$ after treatment with $70 \%, 80 \%$, and $90 \%$ of the minimum inhibitory concentration $(300 \mu \mathrm{g} / \mathrm{mL}$ for all ATCC strains) of trans-cinnamaldehyde respectively. Smaller reductions were observed with respect to the biofilms of the clinical isolate at $73 \%$, $80 \%$, and $84 \%$ after treatment with $70 \%, 80 \%$, and $90 \%$ of the minimum inhibitory concentration $(400-500 \mu \mathrm{g} / \mathrm{mL}$ for this strain) [101].

\subsubsection{Antibiofilm activity of trans-cinnamaldehyde \& its derivatives against Streptococcus pyogenes}

Additionally, the ability of cinnamaldehyde and synthesized derivatives to inhibit the biofilm formation of a clinical isolate of Streptococcus pyogenes (SP5) was examined by Shafreen et al. [102]. Biofilm inhibitory concentration (BIC) values obtained were of the following order; 2-nitrocinnamaldehyde had the lowest BIC of $200 \mu \mathrm{M} /$ $\mathrm{mL}$ (Fig. 1, structure 18) followed by 4-nitrocinnamaldehyde (BIC: $250 \mu \mathrm{M} / \mathrm{mL}$ ) (Fig. 5, structures 29), and then cinnamaldehyde (Fig. 1, structure 1) and 4-(dimethylamino)cinnamaldehyde (both, BIC: $300 \mu \mathrm{M} / \mathrm{mL}$ ) (Fig. 5, structure 30). This group also found, through analysis using confocal laser scanning microscopy (CLSM), that these compounds all led to decreases in biomass, average thickness, and colony size at their respective BIC values. For example, 2-nitrocinnamaldehyde, at its BIC, reduced the biomass from $35.4 \mu \mathrm{m}^{3} / \mu^{2}$ in the untreated SP5 biofilm to $2.1 \mu \mathrm{m}^{3} / \mu \mathrm{m}^{2}$ and reduced the average colony size at the substratum from $180,706.6 \mu \mathrm{m}^{2}$ in the untreated SP5 


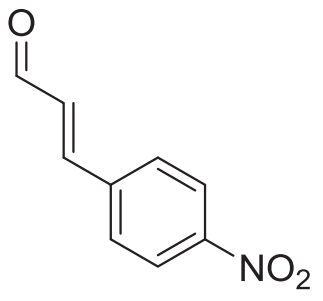

$29^{b}$

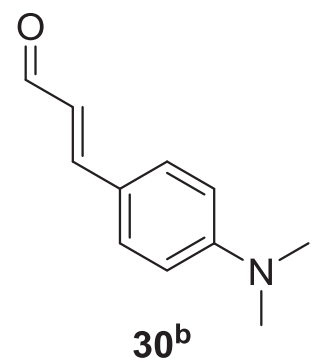

Fig. 5. Cinnamaldehyde derivatives that are known to exhibit antibiofilm properties [102].

biofilm to $409.0 \mu \mathrm{m}^{2}$. Cinnamaldehyde reduced the same control biomass of $35.4 \mu \mathrm{m}^{3} / \mu \mathrm{m}^{2}$ to $3.9 \mu \mathrm{m}^{3} / \mu \mathrm{m}^{2}$ and reduced the average colony size at the substratum from $180,706.6 \mu \mathrm{m}^{2}$ to $13,331.09 \mu \mathrm{m}^{2}$ [102]. This showed the improved activity of 2-nitrocinnamaldehyde relative to cinnamaldehyde at their respective BIC values.

\subsubsection{Antibiofilm activity of trans-cinnamaldehyde against Salmonella Typhimurium}

Silva et al. [103] investigated the effect of cinnamaldehyde on biofilms of Salmonella Typhimurium ATCC 14028. Here the group found that the biomass of these biofilms was significantly reduced by $21 \%$ after exposure to cinnamaldehyde at $312 \mu \mathrm{g} / \mathrm{mL}$ and by $40 \%$ after exposure to cinnamaldehyde at $624 \mu \mathrm{g} / \mathrm{mL}$. The associated metabolic activity of preformed biofilms was also reduced, where treatment with cinnamaldehyde at $312 \mu \mathrm{g} / \mathrm{mL}$ reduced activity by $39 \%$ and treatment with $624 \mu \mathrm{g} / \mathrm{mL}$ reduced activity by $65 \%$. It was also shown that cinnamaldehyde reduced the number of attached cells on polypropylene from $8.03 \log _{10} \mathrm{CFU} / \mathrm{cm}^{2}$ to 6.90 and $5.70 \log _{10} \mathrm{CFU} / \mathrm{cm}^{2}$ after $1 \mathrm{~h}$ exposure to $312 \mu \mathrm{g} / \mathrm{mL}$ and $624 \mu \mathrm{g} / \mathrm{mL}$ cinnamaldehyde respectively. The number of attached cells was assessed by colony count and visualized additionally by scanning electron microscopy (SEM). The efficacy of the antibiofilm properties of cinnamaldehyde was observed to increase as its concentration was increased. This was demonstrated via the change in biofilm biomass upon exposure to $312 \mu \mathrm{g} / \mathrm{mL}$ and $624 \mu \mathrm{g}$ / $\mathrm{mL}$ cinnamaldehyde. Proteomic analysis additionally found that peroxiredoxin, conjugal transfer nickase/helicase TraI, and elongation factor $\mathrm{G}$ were all upregulated in untreated-biofilm cells compared to planktonic cells. Specifically these proteins were upregulated by 7.6fold, 7.6-fold and 7.0-fold, respectively and their expression decreased as a function of cinnamaldehyde concentration, which was administered at a concentration of $624 \mu \mathrm{g} / \mathrm{mL}$. Thus, these differentially expressed proteins have the potential to be possible targets in new therapeutic strategies for the treatment and prevention of $S$. Typhimurium biofilm formation [103].

\subsubsection{Effect of trans-cinnamaldehyde on the morphology of bacterial biofilms}

Aside from the preventative and inhibitory action exhibited by cinnamaldehyde on a range of bacterial biofilms, its effects on the morphology of biofilms have also been examined using CLSM and SEM. Examples of such studies include that by Kim et al. [95] who, using SEM, observed a clear reduction in the production of fimbriae at $0.01 \%$ $\mathrm{v} / \mathrm{v}$ cinnamaldehyde and cinnamon bark oil. Fimbriae are important for EHEC biofilm formation as they aid in the maturation process and facilitate the production of dense biofilms [104]. Also, few biofilm cells were observed to attach to nylon filters in the presence of cinnamaldehyde, and overall the SEM results suggested biofilm inhibition was caused by the decrease in fimbriae production [95]. Using CLSM, Niu and Gilbert [94] observed that E. coli ATCC 33456 cells were elongated with visible signs of induced physical stress after administration of cinnamaldehyde at $2.17 \mathrm{mM}$. Five parameters, which characterize biomass, were calculated by COMSTAT to analyze biofilm structure with and without treatment; total biomass, maximum biofilm thickness, substratum coverage, surface-to-biovolume ratio, and average diffusion distance. A decrease in three of these five parameters was observed after administration of cinnamaldehyde compared to biofilms grown on LB medium alone. For example, maximum thickness of the biofilm was reduced from approximately $46.2 \mu \mathrm{M}$ to approximately 18.3 $\mu \mathrm{M}$ [94]. Using CLSM images, Albano et al. [101] observed that in the absence of trans-cinnamaldehyde, S. epidermidis 35,984 cells formed a dense biofilm composed largely of viable cells. After treatment with trans-cinnamaldehyde, the thickness of the biofilm was reduced significantly with a notable alteration in morphology, the effect of which increased with increasing trans-cinnamaldehyde concentration. For example, in the presence of $25 \%$ minimum inhibitory concentration (where the MIC was determined as $300 \mu \mathrm{g} / \mathrm{mL}$ ) biofilm formation was still present, but with a larger number of non-viable cells. This was compared with exposure to 50 and $90 \%$ MIC, where biofilm formation was prevented and the bacterial cell growth was reduced with few colonies found. The structural changes observed indicated to the authors that a decrease in cell density and biofilm depth had occurred [101].

Both CLSM and SEM techniques were employed by Li et al. [99] to assess the effect of cinnamaldehyde on P. fluorescens biofilm formation. Using light microscopy, this group observed that without treatment $P$. fluorescens formed a dense biofilm with a convex shape. There was a visible reduction in bacterial aggregation and number of microcolonies observed after treatment with cinnamaldehyde, the effect of which increased with increasing cinnamaldehyde concentration ranging from 0.025 to $0.1 \mu \mathrm{L} / \mathrm{mL}$. SEM images showed a disruption in the biofilm architecture over time after treatment with cinnamaldehyde (concentration ranging from 0.025 to $0.1 \mu \mathrm{L} / \mathrm{mL}$ ). Gaps were observed in the biofilm at higher cinnamaldehyde concentrations (e.g. at $0.1 \mu \mathrm{L} /$ $\mathrm{mL}$ ), confirming the antibiofilm activity of cinnamaldehyde [99]. Additionally, Silva et al. [103] observed through the use of SEM, that the $S$. Typhimurium ATCC 14028 biofilm structure was disrupted by treatment with $624 \mu \mathrm{g} / \mathrm{mL}$ cinnamaldehyde. Here, SEM images showed diffuse cells and lower adherence to polypropylene compared with untreated biofilms. Moreover, the absence of cell aggregates was observed [103].

\subsection{Anti-quorum sensing activity of cinnamaldehydes}

Quorum sensing (QS) controls an array of prokaryotic phenotypes such as enzyme secretion, bioluminescence, virulence factor production, and even biofilm production. It is a process that occurs extensively in both Gram-positive and -negative bacteria, where autoinducer (AI) molecules allow the bacteria to sense cell population density [105]. There is a need for new antipathogenic agents and the communication system in bacteria presents a promising target, which could potentially decrease the rate of resistance by avoiding the extensive use of antibiotics while successfully inactivating bacterial pathogenicity $[106,107]$. As a result, the QS inhibitory activity of cinnamaldehyde and its derivatives has been studied across a range of bacteria.

\subsubsection{Anti-quorum sensing effect of trans-cinnamaldehyde on E. coli and Vibrio harveyi}

Niu et al. [105] explored the effect of subinhibitory concentrations (that is, concentrations that had no inhibitory effect on the growth of bacterial cells) of cinnamaldehyde on quorum sensing in E. coli and Vibrio harveyi. Here, the authors found that LuxR-mediated transcription from the $\mathrm{P}_{\text {lux }}$ promoter was inhibited by $70 \%$ after administration of cinnamaldehyde $(200 \mu \mathrm{mol} / \mathrm{L})$. In addition, $100 \mu \mathrm{mol} / \mathrm{L}$ of cinnamaldehyde was shown to reduce the bioluminescence of the AI-2 bioreporter $V$. harveyi BB170 by $62 \pm 2 \%$. This group also showed that cinnamaldehyde $(200 \mu \mathrm{mol} / \mathrm{L})$ only possessed a slight inhibitory effect of $8 \pm 3 \%$ on LasR promoter activity. The authors measured LasR promoter activity via the reduction of specific fluorescence of the $\mathrm{P}_{\text {lasR }}{ }^{-}$ 
gfp bioreporter, E. coli ATCC 33456 pMHLAS [105]. In addition, Yap et al. [107] reported on the ability of Cinnamomum verum bark essential oil to inhibit both $E$. coli [pSB1075] and E. coli [pSB401] related to its anti-QS ability. E. coli [pSB1075] and E. coli [pSB401] carry the lasR and luxR receptor gene respectively. In this study, the bioluminescence was recorded over a $24 \mathrm{~h}$ period and concentrations of $0.01 \%(\mathrm{v} / \mathrm{v})$ cinnamon bark oil reduced $E$. coli [pSB401] bioluminescence from $1.75 \times 10^{6} \mathrm{RLU} / \mathrm{OD}_{495}$ in the untreated cells to less than $0.575 \times 10^{6}$ $\mathrm{RLU} / \mathrm{OD}_{495}$. At the end of the same observation period, all three concentrations of cinnamon bark oil investigated $(0.005 \%, 0.0075 \%$ and $0.01 \% \mathrm{v} / \mathrm{v}$ ), reduced the bioluminescence of E. coli [pSB1075] from approximately $7.0 \times 10^{3} \mathrm{RLU} / \mathrm{OD}_{495}$ in the untreated control to approximately $1.0 \times 10^{3} \mathrm{RLU} / \mathrm{OD}_{495}$ [107].

\subsubsection{Anti-quorum sensing effect of trans-cinnamaldehyde and its derivatives on Vibrio harveyi}

G. Brackman et al. [106] showed that cinnamaldehyde, as well as some derivatives, affected AI-2 based QS in Vibrio harveyi BB170 by decreasing the ability of LuxR to bind to its target promoter sequence in a concentration-dependent manner. Cinnamaldehyde and a synthetic derivative 2-nitrocinnamaldehyde (Fig. 1, structure $1 \&$ 18) were shown to be the most active compounds, which inhibited bioluminescence in Vibrio harveyi BB170 by $65 \pm 13 \%$ and $62 \pm 7 \%$, respectively at $100 \mu \mathrm{M}$ concentration in both cases (recorded $6 \mathrm{~h}$ after the addition of both compounds) [106]. More recently, in 2011, G. Brackman et al. [70] explored this mechanism of action further by conducting a structure-activity relationship of synthesized cinnamaldehyde analogues as AI-2 based QS inhibitors in Vibrio spp. The group assessed the inhibition of QS activity through exploration of the ability to target LuxR and restrict its DNA-binding ability. It was suggested that those analogues containing an $\alpha, \beta$-unsaturated acyl group (Fig. 1, structure 18 \& 19) which can potentially act as Michael acceptors, were found to possess greater activity. For example, at $100 \mu \mathrm{M}$ concentration, 3,4-dichlorocinnamaldehyde (Fig. 1, structure 19), 2nitrocinnamaldehyde (Fig. 1, structure 18), and cinnamaldehyde inhibited the bioluminescence of $V$. harveyi BB170 by $99 \pm 1 \%$, $62 \pm 7 \%$, and $65 \pm 13 \%$ respectively, relative to the untreated control. However, analogues that did not possess an $\alpha, \beta$-unsaturated acyl group, 3-phenylpropionaldehyde for example (Fig. 1, structure 20), did not result in a significant inhibition of the bioluminescence signal in concentrations of up to $100 \mu \mathrm{M}$. This could suggest that trans-cinnamaldehyde and its analogues could act as LuxR-ligands via a Michael addition mechanism. Although direct addition to the carbonyl group could also occur, see section 3.0. Acting as a LuxR ligand, the cinnamaldehydes could yield a modified protein that would likely result in the reduced ability to bind to DNA. One such way the reduction of DNAbinding ability was presented in this study was using $\mathrm{K}_{\mathrm{d}}$ values, which were calculated as the concentration of LuxR at the half-maximal fractional change in fluorescence anisotropy. In the absence of transcinnamaldehyde or its derivatives, a $\mathrm{K}_{\mathrm{d}}$ of approximately $25 \mathrm{nM}$ was recorded. However, in the presence of $50 \mu \mathrm{M}$ cinnamaldehyde, 2-nitrocinnamaldehyde, and 3,4-dichlorocinnamaldehyde, a $\mathrm{K}_{\mathrm{d}}$ of approximately 40,60 , and $225 \mathrm{nM}$ respectively was recorded [70].

\subsubsection{Anti-quorum sensing effect of trans-cinnamaldehyde on Pseudomonas fluorescens.}

$\mathrm{T}$. Li et al. [99] investigated the inhibitory ability of cinnamaldehyde at sublethal concentrations against QS-controlled virulence factors in a different bacterium, Pseudomonas fluorescens. Here the group focused on the inhibition of extracellular protease, biofilm formation, as well as swimming and swarming motility, all of which were shown to be inhibited by the administration of trans-cinnamaldehyde. Violacein production was used as a means of determining the inhibitory action on QS itself, which was inhibited in a concentration-dependent manner by a maximum of $51.03 \%$ at the highest concentration of cinnamaldehyde examined of $0.1 \mu \mathrm{L} / \mathrm{mL}$. Though cinnamaldehyde exhibited anti-QS activity, it was shown not to affect the production of AHLs ( $N$-acylhomoserine lactones) by $P$. fluorescens using GC-MS in concentrations up to $0.1 \mu \mathrm{L} / \mathrm{mL}$. This was deemed surprising by the authors as AHLs are associated with QS and its ability to control virulence factors. They rationalized these results by suggesting that cinnamaldehyde acts as an AHL antagonist, modifying or inhibiting QS by preventing AHL binding to their receptors. Additionally, and in agreement with previous reports, the LuxR-type protein of this bacterium was implicated as a possible mechanism of action in terms of its inhibition of QS using molecular docking analysis [99].

4.3.4. Anti-quorum sensing effect of trans-cinnamaldehyde and its derivatives on Streptococcus pyogenes

Cinnamaldehyde along with synthetic 2-nitrocinnamaldehyde (Fig. 1, structure 18), 4-nitrocinnamaldehyde and 4-dimethylaminocinnamaldehyde (Fig. 5, structures 29 \& 30) have also been evaluated for their inhibition of LuxS, including in Streptococcus pyogenes. Here, Shafreen et al. [102] employed molecular modelling, docking, dynamics, and free-energy calculations as part of their study. LuxS is an important protein, being highly conserved and prevalent in an array of bacteria [108], and is involved in the synthesis of AI-2 signalling molecules which facilitate intraspecies and interspecies QS [102]. Hence, LuxS represents a promising target for antipathogenic agents and the results of quantitative polymerase chain reaction (qPCR) analysis in a study by Shafreen et al. [102] showed that the transcripts treated with cinnamaldehydes at their respective biofilm inhibitory concentrations showed reduced LuxS expression. In the case of the untreated control, a normalized signal intensity of 5.00 was recorded, which was reduced to less than 0.5 after administration of $200 \mu \mathrm{M} / \mathrm{mL}$ 2-nitrocinnaamldehyde and to approximately 0.5 with $300 \mu \mathrm{M} / \mathrm{mL}$ 4-dimethylaminocinnamldehyde. The normalized signal intensity after 4nitrocinnamaldehyde administration of $250 \mu \mathrm{M} / \mathrm{mL}$ was also reduced but to a lesser extent to 1.00 . The lowest inhibition was recorded after $300 \mu \mathrm{mol} / \mathrm{mL}$ cinnamaldehyde administration, which reduced the LuxS expression normalized signal intensity to approximately 1.50 . Overall, the data generated supported the potential use of cinnamaldehyde and its derivatives against QS-mediated infections caused by $S$. pyogenes [102].

4.3.5. Anti-quorum sensing effect of trans-cinnamaldehyde and its derivatives on Cronobacter sakazakii

Amalarajou et al. [100] found, using reverse transcription (RT)qPCR, that trans-cinnamaldehyde was able to significantly downregulate the expression of eight genes that have previously been linked to biofilm formation in Cronobacter sakazakii. In this study, bcs $A$ and luxR were shown to be the most-downregulated by 20.83 fold and 10.42 fold respectively, after exposure to $560 \mu \mathrm{M}$ trans-cinnamaldehyde. This compares to other genes that were downregulated by a maximum of 1.72 fold after treatment with trans-cinnamaldehyde at the same concentration (in the case of $f(i D$ ). Interestingly, these genes are also linked to the QS ability of C. sakazakii [100], showing how the mechanisms of action exhibited by trans-cinnamaldehyde and its derivatives in different bacteria can overlap.

\subsection{Cell constituent release and loss of cell membrane integrity}

In their recent review on essential oils as antimicrobials in foods, Rao et al. [109] discussed how the disruption of the cell membrane permeability inactivates the bacteria by facilitating the infiltration of ions and organic molecules from outside the cell. This eventually leads to the loss of membrane integrity, which is critical for microbial survival [109]. Additionally, when the cell membrane is disrupted some of the intracellular cell constituents are released, and the monitoring of this release can serve as a means of evaluating the effectiveness of antimicrobial agents, as well as giving valuable insight into its mechanism of action $[109,110]$. In this review, these studies have broadly 
been divided into two sections, one where all discussed reports involved E. coli and one where all discussed reports involved Staphylococcus spp. In some cases, authors have presented reports on the use of both E.coli and Staphylococcus spp. under the same experimental conditions. In this review, such reports involving both of these bacteria have been discussed in the Staphylococcus spp. section 4.4.2.

\subsubsection{Cell membrane integrity studies involving $E$. coli}

The release of cell constituents can be experimentally monitored in various ways. One such method is to monitor the release of microbial cell constituents by measuring the UV-absorbance of cell cultures at $260 \mathrm{~nm}$, which is the wavelength at which materials such as proteins and nucleic absorb [111,112]. Proteins and nucleic acids are present throughout the membrane and cytoplasm of the bacterial cells. Proteins facilitate key structural functions, while nucleic acids carry unique genetic information, and both are involved in critical processes such as translation, transcription, and DNA replication [110]. This approach has been used by Oussalah et al. [113] to measure the release of cell constituents from E. coli $\mathrm{O} 157: \mathrm{H7}$ as well as and L. monocytogenes after treatment with Chinese cinnamon, the major component of which is cinnamaldehyde. A significant release of cell constituents was recorded across all concentrations of Chinese cinnamon administered, the highest being observed at $0.1 \% \mathrm{v} / \mathrm{v}$ at which the $\mathrm{OD}_{260 \mathrm{~nm}}$ recorded increased by approximately 4 -fold for both bacteria. The release of cellular constituents was also observed to increase with increasing concentration of Chinese cinnamon essential oil [113].

The monitoring of intracellular $\mathrm{pH}$ of cells after exposure to antimicrobial agents is also indicative of cell membrane permeabilization [113]. Intracellular $\mathrm{pH}$ is a vital parameter for the regulation of many cellular processes, including DNA transcription, protein synthesis, and enzyme activity [114]. Oussulah et al. [113] also showed that Chinese cinnamon oil significantly reduced the intracellular $\mathrm{pH}$ of $E$. coli O157:H7 and also L. monocytogenes. With respect to E. coli O157:H7, the intracellular $\mathrm{pH}$ of cells decreased significantly on increasing Chinese cinnamon oil concentration, while this effect was less pronounced with regard to L. monocytogenes cells. Untreated E. coli cells had an intracellular $\mathrm{pH}$ of 7.25 , which decreased to 5.16 on administration of $0.025 \% \mathrm{v} / \mathrm{v}$ Chinese cinnamon oil. The intracellular $\mathrm{pH}$ decreased further with increasing concentration of the Chinese cinnamon oil to 5.07 and 4.87 , at $0.05 \% \mathrm{v} / \mathrm{v}$ and $0.1 \% \mathrm{v} / \mathrm{v}$ respectively. For L. monocytogenes, a concentration of $0.025 \% \mathrm{v} / \mathrm{v}, 0.05 \% \mathrm{v} / \mathrm{v}$, and $0.1 \% \mathrm{v} / \mathrm{v}$ of Chinese cinnamon oil decreased the intracellular $\mathrm{pH}$ from 6.23 to 5.34 , to 5.12 , and to 5.13 respectively. Therefore, the change in intracellular $\mathrm{pH}$ caused by Chinese cinnamon oil was greater for E. coli O157:H7 than L. monocytogenes. In both cases, the authors suggest that the effect of Chinese cinnamon oil on the intracellular $\mathrm{pH}$ was indicative of its action on the cytoplasmic membrane [113]. Similarly, Turgis et al. [111] investigated the antimicrobial activity of mustard essential oil on E. coli 0157:H7 and Salmonella typhi and saw that this essential oil also significantly reduced the intracellular $\mathrm{pH}$ in both strains [111].

It is not just the release of $260 \mathrm{~nm}$-absorbing materials that is indicative of bacterial cell membrane integrity. A number of other materials are affected as a result of the permeabilization of cell membranes. Hossain et al. [115] utilized an automated HS-SPME technique coupled with GC-MS in order to identify, and in part quantify, the metabolites released as a result of administration of cinnamaldehyde to E. coli BL21 cells. Approximately 25 different compounds such as indole, alkanes, and organic acids were observed after the addition of $2 \mathrm{~g}$ / L cinnamaldehyde [115]. In another study, Mousavi et al. [116] used a SPME - LC - MS platform to evaluate the changes induced by different doses of cinnamaldehyde in different stages of $E$. coli growth and found that compounds related to the TCA cycle, fatty acids, glycolysis, amino acids metabolism, cell membrane, and protein synthesis were all affected by cinnamaldehyde. The results indicated that cinnamaldehyde, at a concentration of $100 \mathrm{mg} / \mathrm{L}$, interacts with the membrane and the proteins embedded inside. At a higher concentration of $2000 \mathrm{mg} / \mathrm{L}$, cinnamaldehyde was found to diffuse inside the cell affecting the cytoplasmic enzymes and transcriptome, and disrupting the membrane leading to cell death [116].

In 2015, Yap et al. [107] proposed that the main mode of action of Cinnamomum verum bark essential oil against a multi-drug resistant $E$. coli strain is through the disruption of the bacterial membrane both at lethal and sublethal concentrations. This was based on evidence gained, for example, through zeta potential measurements as a means of monitoring the bacterial surface charge before and after Cinnamomum verum bark essential oil treatment. The untreated $E$. coli J53 R1 sample had a negative surface charge of $-15 \mathrm{mV}$, whereas treatment with $0.02 \%$ cinnamon bark essential oil saw this reduce to below $-13 \mathrm{mV}$. Here the authors propose that irreversible damage occurs as a result of acidifying and denaturing the proteins associated with the cell membrane, which in turn is caused by the accumulation of essential oil components [107].

Analysis of electrical conductivity in bacterial suspensions is also indicative of the action of antibacterial agents on the cell membrane. The bacterial plasma membrane facilitates the passage of small ions such as $\mathrm{K}^{+}$and $\mathrm{Na}^{+}$, which are necessary electrolytes that enable cell membrane functions and facilitates normal enzymatic activity [117]. Maintenance of ion homeostasis is an important aspect in maintaining the energy status of the cell and it is crucial to membrane-coupled energy-dependent processes including regulation of metabolism, solute transport, control of turgor pressure, and mobility [118]. Therefore, even relatively minor alterations to the structure of membranes and membrane integrity can have a detrimental effect on cell metabolism and consequently lead to cell death [118]. He et al. [119] monitored the relative electrical conductivity of $E$. coli suspensions after treatment with varying concentrations of isolated cinnamaldehyde and observed a significant increase in these values post treatment. The group recorded relative electric conductivity values for $E$. coli suspensions, which indicate the change of permeability for the $E$. coli cells, of $35.537 \pm 0.242 \%$ after exposure to $0.31 \mathrm{~g} / \mathrm{L}$ cinnamaldehyde for $2.5 \mathrm{~h}$. This group note that the conductivity values increased with longer incubation times, thus implying an increased in the permeabilization of the cell membrane over time and with higher concentrations of cinnamaldehyde [119]. Additional results obtained by this group suggested that cinnamaldehyde not only permeabilises the cell membrane of E. coli cells but also oxidizes it [119]. One such way of measuring this is by analysis of malondialdehyde content. Malondialdehyde is normally generated as a by-product during the oxidation of cell membrane, and its content reflects the degree of peroxidation of cell membrane lipid. The malondialdehyde content in this experiment was observed to increase with increasing cinnamaldehyde concentration and increasing treatment time. For example, the content of malondialdehyde obtained from the control was $0.435 \pm 0.051 \mathrm{nmol} /$ mgprot after $2 \mathrm{~h}$, and it increased to $2.322 \pm 0.154$ and $2.580 \pm 0.256 \mathrm{nmol} / \mathrm{mgprot}$ when $E$. coli was treated with $0.2325 \mathrm{~g} / \mathrm{L}$ and $0.31 \mathrm{~g} / \mathrm{L}$ cinnamaldehyde respectively [119]. Superoxide dismutase (SOD) content was also monitored. SODs are enzymes that play a critical role in metabolizing $\mathrm{O}_{2}{ }^{--}$, preventing oxidizing chain reactions that cause extensive damage, and are involved in such activities as preventing the formation of reactive oxygen species like hydrogen peroxide [120]. In this experiment, the total SOD activity without cinnamaldehyde treatment was $95.718 \pm 0.090 \mathrm{U} /$ mgprot after $1 \mathrm{~h}$, which increased to $108.460 \pm 0.298$ and $113.192 \pm 1.469 \mathrm{U} / \mathrm{mgprot}$ with treatments of $0.2325 \mathrm{~g} / \mathrm{L}$ and $0.31 \mathrm{~g} / \mathrm{L}$ cinnamaldehyde respectively. The authors subsequently suggested that cinnamaldehyde oxidizes the unsaturated fatty acids of the cell membrane, causing a larger number of active oxygen radicals to be generated, which in turn causes an increase in SOD activity to resist this harm [119]. The above reports indicate that treatment with cinnamaldehyde can result in a permeabilized cell membrane and that such membrane permeabilization has a number of effects that can be monitored experimentally. In 2019, Doyle et al. [129] reported the effect of trans-cinnamaldehyde and some 
derivatives, specifically $p$-methoxycinnamaldehyde and $p$-bromocinnamaldehyde, on cell membrane permeability. This study examined the bacteriostatic activity of fifteen cinnamaldehyde derivatives against $E$. coli as well as $S$. aureus, and found that p-bromocinnamaldehyde exhibited the highest activity against both bacteria. In order to explore the relationship between bacteriostatic activity and cell wall/membrane leakage, a $S$. aureus or $E$. coli culture was monitored after 2-, 4- and 6hours incubation with each cinnamaldehyde, where results were expressed in terms of protein and amino acid leakage. The amount of leakage observed was very different across the three cinnamaldehydes examined. For both bacteria, trans-cinnamaldehyde caused the highest leakage of amino acids and proteins, though did not exhibit the greatest bacteriostatic activity of the derivatives examined. Thus bacteriostatic activity did not directly correlate with an ability to induce leakage, suggesting that while cinnamaldehydes may be capable of interacting with the cell wall of both bacteria it may not be the primary antibacterial mechanism of action.

\subsubsection{Cell membrane integrity studies involving Staphylococcus spp.}

Shen et al. [121] studied the mechanism of action of cinnamaldehyde on $S$. aureus and $E$. coli by measuring the UV-absorbance of cell cultures at $260 \mathrm{~nm}$ and similarly observed the significant release of $260 \mathrm{~nm}$ absorbing materials from both strains. This occurred quickly after they were exposed to cinnamaldehyde and reached a plateau after 2 and $4 \mathrm{~h}$, respectively. The absorption values, at $4 \mathrm{~h}$, for the $E$. coli treated with $0.31 \mathrm{mg} / \mathrm{mL}$ cinnamaldehyde was 3.55 , which is considerably higher than the control of approximately 0.1 at the same timepoint. The absorption values, at $2 \mathrm{~h}$, for the $S$. aureus treated with $0.31 \mathrm{mg} / \mathrm{mL}$ cinnamaldehyde was 3.00 , which was also considerably higher than the control of approximately 0.25 at the same timepoint [121].

Kwon et al. [13] also measured the UV-absorbance of cell cultures at $260 \mathrm{~nm}$. This group noted the significant leakage of proteins by $S$. aureus, but not $B$. cereus, over a $120 \mathrm{~min}$ incubation period after exposure to cinnamaldehyde, and used the Bradford method to investigate this. Protein leakage was recorded as over $9 \mu \mathrm{g} / \mathrm{mL}$ after exposure to $0.4 \mathrm{~mL} / \mathrm{L}$ cinnamaldehyde after $120 \mathrm{~min}$ of incubation. This was approximately $3 \mu \mathrm{g} / \mathrm{mL}$ higher than the control. In addition, the protein leakage from $S$. aureus was observed to increase gradually during the 120 min incubation period [13].

In their 2015 publication, Shen et al. [121] also monitored $\beta$-galactosidase activity in $S$. aureus, as well as E. coli, so as to evaluate inner membrane permeability after exposure to cinnamaldehyde. $\beta$-Galactosidase is an example of an intramembranous material that would not be leaked unless the cell membrane is damaged. Therefore, how effective cinnamaldehyde is at permeabilizing the inner membranes of $E$. coli and $S$. aureus could be determined by detecting cytoplasmic $\beta$-galactosidase in the bacterial suspension. To do this, Shen et al. assessed the hydrolysis of the substrate ONPG (o-nitrophenyl galactopyranoside), which when hydrolysed by $\beta$-galactosidase produces a coloured product that can be detected spectrophotometrically at $420 \mathrm{~nm}$. The group found that $\beta$-galactosidase activity increased as the cinnamaldehyde concentration was increased, and thus it could be suggested that the level of inner membrane permeability caused by treatment with cinnamaldehyde is dependent on its concentration. The $\beta$-galactosidase activity of $E$. coli cells treated with $0.31 \mathrm{mg} / \mathrm{mL}$ cinnamaldehyde at $2 \mathrm{~h}$ was $0.538932 \pm 0.000577 \mathrm{U} / \mathrm{mL}$, compared to the control of approximately $0.42 \mathrm{U} / \mathrm{mL}$ at the same timepoint. The $\beta$-galactosidase activity of $S$. aureus cells treated with $0.31 \mathrm{mg} / \mathrm{mL}$ of trans-cinnamaldehyde at $1 \mathrm{~h}$ was $0.344472 \pm 0.000000 \mathrm{U} / \mathrm{mL}$, compared to the control of approximately $0.25 \mathrm{U} / \mathrm{mL}$ at the same timepoint [121].

Shen et al. [121] also analyzed the electrical conductivity values of $S$. aureus and $E$. coli suspensions after exposure to cinnamaldehyde and observed that both strains showed higher conductivity values after administration of cinnamaldehyde than that of the control group. The group also noted that this effect increased with increasing cinnamaldehyde concentration, with the exception of one concentration. This rapid rise trend was observed in both strains, where the conductivity values of $S$. aureus increased significantly at the $0-1 \mathrm{~h}$ timepoint. A similar significant increase occurred for $E$. coli cells, but at a slightly later $0-2 \mathrm{~h}$ timepoint, in agreement to that concluded by $\mathrm{He}$ et al [119] in section 4.4.1. The conductivity value of $E$. coli treated with $0.31 \mathrm{mg} / \mathrm{mL}$ cinnamaldehyde was $9.673 \pm 0.011547 \mu \mathrm{s} / \mathrm{cm}$ at the two-hour timepoint, compared to the control conductivity value of approximately $8.6 \mu \mathrm{s} / \mathrm{cm}$. For $S$. aureus, treatment with $0.31 \mathrm{mg} / \mathrm{mL}$ cinnamaldehyde generated a conductivity value of approximately $11.25 \pm 0.005568 \mu \mathrm{s} / \mathrm{cm}$ at the 1 - $\mathrm{h}$ timepoint, which compares to the control value of approximately $9.7 \mu \mathrm{s} / \mathrm{cm}$. As a result, the authors suggest that the higher the cinnamaldehyde concentration, then the greater the extent of damage to the bacterial cell membrane [121].

These findings were in agreement with with those made by Zhang et al. [110], who analyzed changes in relative electric conductivity after exposure of $S$. aureus and E. coli cells to cinnamon essential oil. The group observed a rapid increase in the electric conductivity of suspensions of both bacteria upon treatment, corresponding to the leakage of small electrolytes. Here the relative electric conductivity values, which was used to express the change in permeability, obtained for $E$. coli and S. aureus reached $60 \%$ and $79.4 \%$ respectively at the sevenhour timepoint after exposure to $4.0 \mathrm{mg} / \mathrm{mL}$ and $2.0 \mathrm{mg} / \mathrm{mL}$ cinnamon essential oil respectively. This was relative to the control which reached a relative conductivity value of less than $5 \%$ for $E$. coli and $10 \%$ for $S$. aureus respectively. The authors note that their results indicate that treatment with cinnamon essential oil causes an increase in the permeability of cell membrane, causing cellular leakage [110]. This is in agreement with the findings of Albano et al. [101] who studied the effect of trans-cinnamaldehyde on S. epidermis ATCC 35984 cell membrane permeability. It was observed that the administration of $300 \mu \mathrm{g} /$ $\mathrm{mL}$ cinnamaldehyde resulted in an increase of relative electric conductivity of $41 \%$ after incubation for $8 \mathrm{~h}$ compared to the control where less than $5 \%$ relative electric conductivity was observed. This therefore indicated that trans-cinnamaldehyde was capable of permeabilizing the cell membrane, and this effect was observed to increase with longer incubation times and higher cinnamaldehyde concentrations [101].

\subsection{Morphological changes induced by exposure to cinnamaldehyde}

The morphological changes that occur in bacterial cells as a result of exposure to trans-cinnamaldehyde has been investigated across a range of bacteria. For example, Nazarro et al. [10] have described a number of bacteria that trans-cinnamaldehyde is capable of eliciting morphological changes on, including S. typhimurium, Pseudomonas spp., and Brochothrix thermosphacta [10]. For the most part, the morphological changes that occur as a result of trans-cinnamaldehyde exposure has been analyzed by scanning or transmission electron microscopy (SEM or TEM respectively), and will be discussed in the following sections. To the best of our knowledge, there are no studies investigating the changes to bacterial cell morphology induced by exposure to transcinnamaldehyde derivatives.

\subsubsection{Morphological changes induced with S. aureus and E. coli}

Shen et al. [121] employed SEM to analyze the effect of cinnamaldehyde on the membranes of $S$. aureus ATCC3101 and E. coli ATCC8735 cells at the minimum inhibitory concentration (MIC) $(0.31 \mathrm{mg} / \mathrm{mL}$ in both cases). The group observed a number of changes in both cells after treatment with cinnamaldehyde for 6-8 h, noting in particular the effects on $S$. aureus cells including splitting of some cells, development of deep wrinkles and distortion, deterioration of the cell wall, and extensive cell lysis. The external structure of $E$. coli was also affected but to a lesser extent, namely a rough cell membrane with some particulate matter and some swelling was observed after treatment with trans-cinnamaldehyde at its MIC. The authors note that the ability to induce these morphological changes is likely as a result of 
cinnamaldehyde being capable of penetrating the cell envelope and consequently alter its structure [121].

Shen et al. [121] used TEM to observe a number of changes with respect to $E$. coli after treatment with cinnamaldehyde at its MIC for 6-8 h, including the separation of cytoplasmic membrane from the cell wall, cell wall and cell membrane lysis, cytoplasmic content leakage, polarization and condensation, as well as distortion of the cell. Similar changes where observed with respect to $S$. aureus, notably the disintegration of the cell as well as leakage and polarization of cytoplasmic content, which was observed after exposure of cells to cinnamaldehyde at its MIC. The authors note that these effects correlate with the ability of hydrocarbons, such as cinnamaldehyde, to interact with hydrophobic structures such as bacterial membranes. Importantly, the TEM results show that cinnamaldehyde targets different parts of the cell and so, the antibacterial activity exhibited by cinnamaldehyde is most likely not as a result of one specific mechanism [121].

\subsubsection{Morphological changes induced with $S$. aureus and B. cereus}

Kwon et al. [13] analyzed the morphological changes observed after exposure of cells to cinnamaldehyde using SEM, investigating B. cereus ATCC11778 and $S$. aureus ATCC22954 cells. Conversely to the report by Shen et al., [121] Kwon et al. report no major differences between untreated $S$. aureus cells and those after administration of $0.3 \mathrm{~mL} / \mathrm{L}$ cinnamaldehyde, but importantly a different $S$. aureus strain was used and there was a much shorter incubation time of $1 \mathrm{~h}$ before SEM was applied. However, the morphology of the B. cereus was significantly changed after exposure to cinnamaldehyde at the same concentration, with changes such as the elongation of cells, formation of thinner filaments in which there were no separation of cells, and the formation of incomplete septa between two cells being observed [13].

\subsubsection{Morphological changes induced with $E$. coli and L. monocytogenes}

Oussalah et al. [113], again conversely to the report by Shen et al. [121], showed that after treatment with Chinese cinnamon at $0.05 \%$ (v/v), the appearance of cells of E. coli O157:H7 and L. monocytogenes was unchanged. Importantly, a different $E$. coli strain was used compared to that used by Shen et al. [121] and a much shorter incubation time of $30 \mathrm{~min}$ was applied in this study before implementation of TEM analysis. However, the authors note that other results presented in this study showed evidence of disruption to the cell membrane in both bacteria, such as an increase in the permeabilization of cells to the dye phosphotungstic acid (1\% (weight/vol), $\mathrm{pH}$ 6), as visualized using TEM, as well as other data already discussed in section 4.4.1 including release of cellular constituents and changes in intracellular $\mathrm{pH}$ [113]. Thus, while there is conflicting evidence in the literature regarding the exact morphological changes that trans-cinnamaldehyde administration induces on cells, it is apparent that certain changes, particularly with respect to those involving the cell membrane, are induced.

\subsection{Effect of cinnamaldehydes on ATP levels}

Adenosine triphosphate (ATP) is a small molecule of critical importance for a range of organisms. It is generated via respiration and is used for such cellular functions as storing and supplying energy, enzymatic reactions, cell signalling, and many other functions that are pertinent to the survival, growth, and replication of cells [122]. There is agreement in the literature on the impact of cinnamaldehyde, whether isolated or as a major component of Chinese cinnamon oil, on ATP levels. There are numerous reports that detail a significant decrease in the levels of intracellular ATP, post treatment and without causing an increase in extracellular ATP levels, across a range of bacteria including $E$. coli $[18,113,123]$, Salmonella typhimurium [123], Listeria monocytogenes [14,18,113], and Map (Mycobacterium avium subsp. paratuberculosis) [124]. Interestingly, trans-cinnamaldehyde has been shown to have no effect on Lactobacillus sakei at concentrations of up to $0.5 \mathrm{M}$ [14]. There is some disparity however as to what can be concluded from these results and what the authors suggest in terms of the effect of transcinnamaldehyde has on the bacterial cell membrane. In order to effectively summarize and review this area of work, the following two sections will cover reports from 1998 to 2006 and from the more recent literature of 2006-2019.

\subsubsection{Effect of cinnamaldehyde on ATP levels (1998-2006)}

Earlier work on understanding the mechanism of action suggested that trans-cinnamaldehyde did not disrupt the outer membrane of bacterial cells $[18,123]$. Helander et al. [123] deduced that trans-cinnamaldehyde could gain access to the periplasm and to the deeper parts of the cell without exerting disintegrative effects on the outer membrane. This was based on evidence obtained experimentally by the authors who noted that even though trans-cinnamaldehyde exhibited good bioactivity, for example it could inhibit the bioluminescence of $P$. leiognathi by around $75 \%$ at concentrations as low as approximately $0.12 \mathrm{mM}$, there was a lack of effect on the size of the intracellular ATP pool during the incubation period at a concentration of $2 \mathrm{mM}$. Additionally, exposure of $E$. coli cells to trans-cinnamaldehyde did not induce the release of outer membrane-associated material, for example it did not affect NPN (1- $N$-phenylnaphthylamine) uptake after $2 \mathrm{mM}$ trans-cinnamaldehyde was administered [123].

Gill and Holley [18] observed that administration of $10 \mathrm{mM}$ transcinnamaldehyde to $E$. coli and $40 \mathrm{mM}$ trans-cinnamaldehyde to $\mathrm{L}$. monocytogenes caused significant decreases in intracellular ATP levels. Here, the treatment of $E$. coli cells with dextrose, the control used in this experiment, had an associated intracellular ATP concentration of approximately $4400 \mathrm{fmol} / \mu \mathrm{g}$ protein after $20 \mathrm{~min}$ incubation and was compared to the intracellular ATP concentration of approximately 1400 $\mathrm{fmol} / \mu \mathrm{g}$ protein after the same incubation period and post treatment with $10 \mathrm{mM}$ trans-cinnamaldehyde. However, the group observed no increase in extracellular ATP concentration experimentally and deduced that this occurrence is inconsistent with membrane permeabilization. They hypothesized that ATP inhibition could represent a secondary factor rather than a primary cause of cell death in this case [18]. Previously, Gill and Holley [14] had hypothesized that trans-cinnamaldehyde could interact with the cell membrane, causing sufficient damage to result in the leakage of small ions, thus affecting the proton motive force, but insufficient damage to result in the leakage of larger cell components such as ATP. This is how the authors explained that no increase in extracellular ATP levels were observed experimentally after exposure of L. monocytogenes cells to $40 \mathrm{mM}$ trans-cinnamaldehyde, though with the same treatment a significant decrease in intracellular ATP levels was observed. Treatment of L. monocytogenes cells with glucose, the control used, had an associated intracellular ATP concentration of approximately $530 \mathrm{fmol} / \mu \mathrm{g}$ protein after $20 \mathrm{~min}$ incubation compared to the intracellular ATP concentration of approximately $50 \mathrm{fmol} / \mu \mathrm{g}$ protein after the same incubation period and post administration of $40 \mathrm{mM}$ trans-cinnamaldehyde. Additionally, the authors noted that these results are consistent with either inhibition of glucose import or inhibition of glycolysis [14].

\subsubsection{Effect of cinnamaldehyde on ATP levels (2006-2019)}

More recent papers postulate that trans-cinnamaldehyde can alter the integrity of bacterial cell membranes. For example, Oussalah et al. [113] reported that the administration of Chinese cinnamon essential oil at its MIC alters the membrane integrity of both $E$. coli and L. monocytogenes cells. This was deduced in part on the basis of cinnamaldehyde's effect on ATP, where a treatment of $E$. coli O157:H7 cells with $0.025 \%(\mathrm{v} / \mathrm{v})$ Chinese cinnamon oil, the lowest concentration examined, caused a significant decrease in intracellular ATP concentration from $1.84 \mathrm{ng} / \mathrm{mL}$ to $1.09 \mathrm{ng} / \mathrm{mL}$, and a slight increase in extracellular ATP concentration from $0.03 \mathrm{ng} / \mathrm{mL}$ to $0.05 \mathrm{ng} / \mathrm{mL}$. Similar observations were also made with respect to treatment of $\mathrm{L}$. monocytogenes with Chinese cinnamon oil. Additionally, its effect on intracellular $\mathrm{pH}$ was monitored, as well as the use of electronic 
microscopy analysis, as previously discussed in sections 4.4.1 and 4.5.3. Both of which support the hypothesis that trans-cinnamaldehyde affects the integrity of bacterial cell membranes [113]. Nowotarska et al. [124] also determined that cinnamaldehyde is capable of disrupting the bacterial membrane based on evidence gained in part from observation of the effect of cinnamaldehyde on ATP. Nowotarska et al. noted, in agreement with previous reports, that cinnamaldehyde significantly decreased intracellular ATP without affecting the extracellular ATP concentration of $0.5 \mathrm{nM}$. The conclusion drawn regarding the ability of cinnamaldehyde to disrupt the bacterial membrane was also based on evidence gained from the implementation of monolayer studies using a Langmuir trough apparatus as well analysis of cellular constituents released after treatment with cinnamaldehyde. For example, the performance of an extracellular phosphate assay on Map cells showed an increase in extracellular phosphate levels in the presence of cinnamaldehyde that was concentration- and time-dependent [124].

Silva et al. [103] reported the effect of cinnamaldehyde against Salmonella Typhimurium ATCC 14028 biofilms and compared the protein patterns of untreated biofilms versus those after treatment with $624 \mu \mathrm{g} / \mathrm{mL}$ cinnamaldehyde using proteomic analysis. One such protein whose expression decreased after cinnamaldehyde exposure was ATP synthase alpha chain protein. This protein is a component of the ATP synthase protein complex that functions in the bacterial cell to assist in the production of ATP. Interestingly, though its expression was increased 6.6-fold in the biofilm itself, after exposure to cinnamaldehyde this protein was not expressed at all. [103] Thus, ATP synthase alpha chain protein is potentially a target of cinnamaldehyde in bacterial cells and causes the reduction in ATP levels that have been experimentally observed.

\subsection{Effect of cinnamaldehydes on ATPase}

ATPases catalyse the hydrolysis of ATP to ADP. There are different types of ATPases which serve important cellular functions. For example, $\mathrm{Na}^{+} / \mathrm{K}^{+}$ATPase, a P-type transport ATPase, is responsible for the generation of ionic transmembrane gradients that are important in such cellular activities such as active transport processes, and the maintenance of intracellular $\mathrm{pH}$ and ion homeostasis [125]. Transport ATPases are a type of ATPase used to transport ions and have common features; they exist in biological membranes, hydrolyze ATP, and transport at least one substance across a biological membrane using energy gained from ATP hydrolysis [126]. Lipophilic compounds, such as cinnamaldehyde, may indirectly influence the pool of adenine nucleotides, due to the interlinking of the proton motive force and phosphate potential via $\mathrm{F}_{0} \mathrm{~F}_{1}$ ATPases. An example of such an adenine nucleotide is ATP, and its depletion has been observed in several cases upon treatment with cinnamaldehyde, as discussed above with respect to intracellular ATP levels. The observation that lipophilic compounds stimulate the activity of proton and/or ion-translocating ATPases may originate from the removal of the proton motive force, limiting ATP hydrolysis [127]. Thus, if the normal activity of ATPases is interrupted, the electrolyte balance of the cell will be affected, which has a direct effect on homeostasis of the cell and results in a decrease in ATP levels [125]. This could possibly even result in the occurrence of cell death if cellular respiration is affected [109].

The effect of trans-cinnamaldehyde on bacterial ATPases has been investigated as a possible the mechanism of action for its antibacterial properties. Gill and Holley [128] investigated the ability of trans-cinnamaldehyde to inhibit membrane bound ATPases of $E$. coli and L. monocytogenes. Increasing concentrations of trans-cinnamaldehyde led to increasingly greater inhibition of ATPase activity in E. coli cell membranes. As the concentration of trans-cinnamaldehyde increased from $0.1 \mathrm{mM}$ to $10 \mathrm{mM}$, the corresponding inhibition of ATPase activity was recorded as less than $10 \%$ to over $85 \%$ respectively. L. monocytogenes ATPase activity was also shown to be significantly inhibited by trans-cinnamaldehyde, but only at the highest concentration of trans- cinnamaldehyde administered of $10 \mathrm{mM}$ [128]. This agrees with the suggestion made by Nazarro et al. [10] in their review paper, that transcinnamaldehyde is an ATPase-inhibitor in bacterial cells. Gill and Holley [128] noted that the observed inhibition of ATPase activity may be due to the non-specific inhibition of membrane-bound or embedded enzymes [128]. Such enzymes not only include ATPases, but also transport proteins, transferases, various oxidreductases, and signaltransducing enzymes [127]. This non-specific inhibition may be caused by the ability of small hydrophobic molecules, such as trans-cinnamaldehyde, to induce changes in protein conformation as a result of hydrophobic interactions [128]. Gill and Holley [14] previously noted that although the inhibition of energy generation processes may not be the sole mechanism of action of trans-cinnamaldehyde or similar molecules, they are the most important. They attribute this to the cells being unable to reproduce or alter their metabolism, in order to adapt to the antimicrobial challenge they are exposed to, as they are no longer capable of generating energy [14].

There are various enzymes in bacterial membranes with associated ATPase activity. Examples include $\mathrm{F}_{0} \mathrm{~F}_{1}$ ATPase, which as discussed above is involved in generating ATP and regulating cellular $\mathrm{pH}$. Although not a bacterial cell study, Usta et al. [125] reported some interesting ATPase results using trans-cinnamaldehyde and rat liver ATPases. This group investigated the effect of trans-cinnamaldehyde on different types of rate liver ATPases, namely P-type $\mathrm{Na}^{+} / \mathrm{K}^{+}$ATPase and CPx-type $\mathrm{Cu}^{2+}$ ATPase. Both ATPases were inhibited by transcinnamaldehyde in a concentration-dependent manner, where a $50 \%$ inhibition of $\mathrm{Na}^{+} / \mathrm{K}^{+}$ATPase activity was recorded at approximately $4.7 \mathrm{mM}$ and a $50 \%$ inhibition of CPx-type $\mathrm{Cu}^{2+}$ ATPase at $0.94 \mathrm{mM}$. Ftype mitochondrial $\mathrm{F}_{0} \mathrm{~F}_{1}$ ATPase was conversely stimulated by $0.37 \mathrm{MM}$ trans-cinnamaldehyde. As such, all three ATPases represent possible intracellular targets for trans-cinnamaldehyde on the basis of this study [125]. Although the ATPases investigated in this study were not bacterial, it possible that trans-cinnamaldehyde could interact with bacterial P-, F- and CPx- classes of ATPases in a similar manner.

To the best of our knowledge, no studies that have been conducted investigating the effect of trans-cinnamaldehyde derivatives on bacterial ATP levels or ATPases. Shreaz et al. [61] studied the effect of cinnamaldehyde along with two if its natural derivatives, coniferyl aldehyde and sinapaldehyde (Fig. 1, structure 15 \& 16), against 65 strains of Candida and all three compounds were found to be effective against all Candida strains tested. MICs of cinnamaldehyde, coniferyl aldehyde, and sinapaldehyde ranged from 100 to $500 \mu \mathrm{g} / \mathrm{mL}, 100$ to $300 \mu \mathrm{g} / \mathrm{mL}$, and 100 to $200 \mu \mathrm{g} / \mathrm{mL}$ respectively. The authors attribute their activity, at least in part, to their ability to inhibit plasma membrane-ATPases, where the inhibition caused by the three cinnamaldehydes at their respective $\mathrm{MIC}_{90}$ concentrations correlated well with that of known plasma membrane-ATPase inhibitors $\mathrm{N}, \mathrm{N}^{\prime}$-dicyclohexylcarbodiimide $(100 \mu \mathrm{M})$ and diethylstilbestrol $(10 \mu \mathrm{M})[61]$.

\section{Conclusion}

In this review, we have presented studies where the antibacterial activity of the naturally occurring compound trans-cinnamaldehyde and its derivatives have been investigated. This work highlights studies where the antibacterial mechanisms of action of trans-cinnamaldehyde, and in some cases that of cinnamaldehyde derivatives, have been explored. At a time when antibiotic resistance is a global threat, there is an urgent need for alternative antibacterial agents than those currently available. Trans-Cinnamaldehyde can be considered a promising research prospect, in part as an antibacterial agent itself due to its modest antibacterial activity across a broad scope of bacteria and low associated toxicity, but perhaps more significantly as a hit compound from which other antibacterial agents can be developed, or as a tool to better understand and develop targets for new antibacterial agents. Some trans-cinnamaldehyde derivatives that have been synthesized have already shown improved antibacterial activity relative to trans- 
cinnamaldehyde. These compounds, and their mechanisms of action, therefore warrant further investigation as potential antibacterial agents and targets. However, the current knowledge on the antibacterial mechanisms of action of these compounds, cinnamaldehyde derivatives in particular, is limited. As such, further studies should be undertaken in order to optimise the potential of these compounds and targets. This review, summarizing the major contributions in this area to date, will aid in the future development of cinnamaldehyde-based antibacterial agents or new agents seeking to exploit similar mechanisms of action. Preliminary results obtained in this area give much promise to future investigations and it is hoped that this review may potentially help contribute to the discovery of new agents with real-world applications in clinical and/or agricultural settings. It is also anticipated that those conducting important studies in other areas of cinnamaldehyde application will find this review useful in terms of summarizing some of the potential biological roles and mechanisms of action for cinnamaldehydes.

\section{Acknowledgements}

The authors would like to thank Maynooth University for funding.

\section{Declaration of Competing Interest}

The authors declare that they have no known competing financial interests or personal relationships that could have appeared to influence the work reported in this paper.

\section{References}

[1] W.T. Langeveld, E.J.A. Veldhuizen, S.A. Burt, Synergy between essential oil components and antibiotics: a review, Crit. Rev. Microbiol. 40 (2014) 76-94.

[2] J.D. Guzman, Natural cinnamic acids, synthetic derivatives and hybrids with antimicrobial activity, Molecules (Basel, Switzerland) 19 (2014) 19292-19349.

[3] L.N. Silva, K.R. Zimmer, A.J. Macedo, D.S. Trentin, Plant natural products targeting bacterial virulence factors, Chem. Rev. 116 (2016) 9162-9236.

[4] A. Cassini, L.D. Högberg, D. Plachouras, A. Quattrocchi, A. Hoxha, G.S. Simonsen, M. Colomb-Cotinat, M.E. Kretzschmar, B. Devleesschauwer, M. Cecchini, D.A. Ouakrim, T.C. Oliveira, M.J. Struelens, C. Suetens, D.L. Monnet, R. Strauss, K. Mertens, T. Struyf, B. Catry, K. Latour, I.N. Ivanov, E.G. Dobreva, A. Tambic Andraševic, S. Soprek, A. Budimir, N. Paphitou, H. Žemlicková, S. Schytte Olsen, U. Wolff Sönksen, P. Märtin, M. Ivanova, O. Lyytikäinen, J. Jalava, B. Coignard, T. Eckmanns, M. Abu Sin, S. Haller, G.L. Daikos, A. Gikas, S. Tsiodras, F. Kontopidou, Á. Tóth, Á. Hajdu, Ó. Guólaugsson, K.G. Kristinsson, S. Murchan, K. Burns, P. Pezzotti, C. Gagliotti, U. Dumpis, A. Liuimiene, M. Perrin, M.A. Borg, S.C. de Greeff, J.C.M. Monen, M.B.G. Koek, P. Elstrøm, D. Zabicka, A. Deptula, W. Hryniewicz, M. Caniça, P.J. Nogueira, P.A. Fernandes, V. Manageiro, G.A. Popescu, R.I. Serban, E. Schréterová, S. Litvová, M. Štefkovicová, J. Kolman, I. Klavs, A. Korošec, B. Aracil, A. Asensio, M. Pérez-Vázquez, H. Billström, S. Larsson, J.S. Reilly, A. Johnson, S. Hopkins, Attributable deaths and disabilityadjusted life-years caused by infections with antibiotic-resistant bacteria in the EU and the European Economic Area in 2015: a population-level modelling analysis, Lancet Infect. Dis. 19 (2019) 56-66.

[5] S. Burt, Essential oils: their antibacterial properties and potential applications in foods - a review, Int. J. Food Microbiol. 94 (2004) 223-253.

[6] J.R. Calo, P.G. Crandall, C.A. O'Bryan, S.C. Ricke, Essential oils as antimicrobials in food systems - a review, Food Control 54 (2015) 111-119.

[7] M.S. Brewer, M. Rojas, Consumer attitudes toward issues in food safety, J. Food Saf. 28 (2008) 1-22.

[8] N. Yossa, J. Patel, P. Millner, Y.M. Lo, Essential oils reduce Escherichia coli O157:H7 and Salmonella on spinach leaves, J. Food Prot. 75 (2012) 488-496.

[9] J. Visvalingam, J.D. Hernandez-Doria, R.A. Holley, Examination of the genomewide transcriptional response of Escherichia coli O157:H7 to Cinnamaldehyde exposure, Appl. Environ. Microbiol. 79 (2013) 942-950.

[10] F. Nazzaro, F. Fratianni, L. De Martino, R. Coppola, V. De Feo, Effect of essential oils on pathogenic bacteria, Pharmaceuticals (Basel, Switzerland) 6 (2013) 1451-1474.

[11] S. Shreaz, W.A. Wani, J.M. Behbehani, V. Raja, M. Irshad, M. Karched, I. Ali, W.A. Siddiqi, L.T. Hun, Cinnamaldehyde and its derivatives, a novel class of antifungal agents, Fitoterapia 112 (2016) 116-131.

[12] N.G. Vasconcelos, J. Croda, S. Simionatto, Antibacterial mechanisms of cinnamon and its constituents: a review, Microb. Pathog. 120 (2018) 198-203.

[13] J.A. Kwon, C.B. Yu, H.D. Park, Bacteriocidal effects and inhibition of cell separation of cinnamic aldehyde on Bacillus cereus, Lett. Appl. Microbiol. 37 (2003) 61-65.

[14] A.O. Gill, R.A. Holley, Mechanisms of bactericidal action of Cinnamaldehyde against Listeria monocytogenes and of Eugenol against L. monocytogenes and Lactobacillus sakei, Appl. Environ. Microbiol. 70 (2004) 5750-5755.

[15] S.A. Baskaran, M.A.R. Amalaradjou, T. Hoagland, K. Venkitanarayanan, Inactivation of Escherichia coli O157:H7 in apple juice and apple cider by transcinnamaldehyde, Int. J. Food Microbiol. 141 (2010) 126-129.

[16] D.F. Firmino, T.T.A. Cavalcante, G.A. Gomes, N.C.S. Firmino, L.D. Rosa, M.G. de Carvalho, F.E.A. Catunda Jr., Antibacterial and Antibiofilm activities of Cinnamomum Sp. essential oil and Cinnamaldehyde: antimicrobial activities, TheScientificWorldJournal 2018 (2018) 7405736.

[17] M. Friedman, Chemistry, antimicrobial mechanisms, and antibiotic activities of cinnamaldehyde against pathogenic bacteria in animal feeds and human foods, J. Agric. Food Chem. 65 (2017) 10406-10423.

[18] A.O. Gill, R.A. Holley, Disruption of Escherichia coli, Listeria monocytogenes and Lactobacillus sakei cellular membranes by plant oil aromatics, Int. J. Food Microbiol. 108 (2006) 1-9.

[19] S.N. Ashakirin, M. Tripathy, U.K. Patil, A.B.A. Majeed, Chemistry and bioactivity of Cinnamaldehyde: a natural molecule of medicinal importance, Int. J. Pharm. Sci. Res. 8 (2017) 2333.

[20] L. Zhu, C. Olsen, T. McHugh, M. Friedman, D. Jaroni, S. Ravishankar, Apple carrot, and Hibiscus edible films containing the plant antimicrobials Carvacrol and Cinnamaldehyde inactivate Salmonella Newport on organic leafy greens in sealed plastic bags, J. Food Sci. 79 (2014) M61-M66.

[21] T.F. He, Z.H. Zhang, X.A. Zeng, L.H. Wang, C.S. Brennan, Determination of membrane disruption and genomic DNA binding of cinnamaldehyde to Escherichia coli by use of microbiological and spectroscopic techniques, $\mathrm{J}$. Photochem. Photobiol. B Biol. 178 (2018) 623-630.

[22] B.-J. Chen, C.-S. Fu, G.-H. Li, X.-N. Wang, H.-X. Lou, D.-M. Ren, T. Shen, Cinnamaldehyde analogues as potential therapeutic agents, Mini Rev. Med. Chem. 17 (2017) 33-43.

[23] P.V. Rao, S.H. Gan, Cinnamon: a multifaceted medicinal plant, Evidence-Based Complement. Altern. Med. 2014 (2014) (642942-642912).

[24] Y. Zhang, S. Li, X. Kong, Relationship between antimold activity and molecula structure of cinnamaldehyde analogues, Bioorg. Med. Chem. Lett. 23 (2013) $1358-1364$.

[25] H.-S. Lee, S.-Y. Kim, C.-H. Lee, Y.-J. Ahn, Cytotoxic and mutagenic effects of Cinnamomum cassia bark-derived materials, J. Microbiol. Biotechnol. 14 (2004) $1176-1181$.

[26] T. Imai, K. Yasuhara, T. Tamura, T. Takizawa, M. Ueda, M. Hirose, K. Mitsumori, Inhibitory effects of cinnamaldehyde on 4-(methylnitrosamino)-1-(3-pyridyl)-1 butanone-induced lung carcinogenesis in rasH2 mice, Cancer Lett. 175 (2002) 9-16.

[27] S.-J. Wu, L.-T. Ng, C.-C. Lin, Cinnamaldehyde-induced apoptosis in human PLC/ $\mathrm{PRF} / 5$ cells through activation of the proapoptotic Bcl-2 family proteins and MAPK pathway, Life Sci. 77 (2005) 938-951.

[28] R. Banjerdpongchai, P. Punyati, A. Nakrob, W. Pompimon, P. Kongtawelert, 4'hydroxycinnamaldehyde from Alpinia galanga (Linn.) induces human leukemic cell apoptosis via mitochondrial and endoplasmic reticulum stress pathways, Asian Pac. J. Cancer Prev. 12 (2011) 593-598.

[29] S.-A. Kim, Y.-K. Sung, B.-M. Kwon, J.-H. Yoon, H. Lee, S.-G. Ahn, S.-H. Hong, 2'Hydroxycinnamaldehyde shows antitumor activity against oral cancer in vitro and in vivo in a rat tumor model, Anticancer Res. 30 (2010) 489-494.

[30] H.-S. Kang, J. Ock, H.-J. Lee, Y.-J. Lee, B.-M. Kwon, S.-H. Hong, Early growth response protein 1 upregulation and nuclear translocation by 2'-benzoyloxycinnamaldehyde induces prostate cancer cell death, Cancer Lett. 329 (2012) 217-227.

[31] M.A. Lee, H.J. Park, H.-J. Chung, W.K. Kim, S.K. Lee, Antitumor activity of 2hydroxycinnamaldehyde for human colon cancer cells through suppression of $\beta$ catenin Signaling, J. Nat. Prod. 76 (2013) 1278-1284.

[32] D.-S. Shin, H.-M. Kim, J.-H. Kim, K.-R. Kim, S.J. Lee, S.-K. Lee, D.C. Han, K.-H. Son, H.-G. Cheon, N.-D. Sung, S.K. Kang, B.-M. Kwon, Synthesis and biological evauation of dimeric cinnamaldehydes as potent antitumor agents, Bioorg. Med. Chem. 14 (2006) 2498-2506.

[33] S.H. Hong, J. Kim, J.-M. Kim, S.-Y. Lee, D.-S. Shin, K.-H. Son, D.C. Han, Y.K. Sung, B.-M. Kwon, Apoptosis induction of 2'-hydroxycinnamaldehyde as a proteasome inhibitor is associated with ER stress and mitochondrial perturbation in cancer cells, Biochem. Pharmacol. 74 (2007) 557-565.

[34] F.F. Gan, Y.S. Chua, S. Scarmagnani, P. Palaniappan, M. Franks, T. Poobalasingam, T.D. Bradshaw, A.D. Westwell, T. Hagen, Structure-activity analysis of 2'-modified cinnamaldehyde analogues as potential anticancer agents, Biochem. Biophys. Res. Commun. 387 (2009) 741-747.

[35] E.-H. Chew, A.A. Nagle, Y. Zhang, S. Scarmagnani, P. Palaniappan, T.D. Bradshaw, A. Holmoren, A.D. Westwell, Cinnamaldehydes inhibit thioredoxin reductase and induce Nrf2: potential candidates for cancer therapy and chemoprevention, Free Radic. Biol. Med. 48 (2010) 98-111.

[36] A.A. Nagle, F.-F. Gan, G. Jones, C.-L. So, G. Wells, E.-H. Chew, Induction of tumo cell death through targeting tubulin and evoking dysregulation of cell cycle regulatory proteins by multifunctional Cinnamaldehydes, PLoS One 7 (2012) e50125.

[37] G. Min, S.-K. Lee, R.-H. Lee, H.-N. Kim, Y.-M. Han, D.C. Han, D.G. Jeong, B.M. Kwon, Rhodanine-based PRL-3 inhibitors blocked the migration and invasion of metastatic cancer cells, Bioorg. Med. Chem. Lett. 23 (2013) 3769-3774.

[38] C.M. Cabello, W.B. Bair, S.D. Lamore, S. Ley, A.S. Bause, S. Azimian, G.T. Wondrak, The cinnamon-derived Michael acceptor cinnamic aldehyde impairs melanoma cell proliferation, invasiveness, and tumor growth, Free Radic. Biol. Med. 46 (2009) 220-231.

[39] N. Motohashi, C. Yamagami, H. Tokuda, Y. Okuda, E. Ichiishi, T. Mukainaka, H. Nishino, Y. Saito, Structure-activity relationship in potentially anti-tumor 
promoting benzalacetone derivatives, as assayed by the Epstein-Barr virus early antigen activation, Mut. Res. Genet. Toxicol. Environ. Mutagen. 464 (2000) $247-254$.

[40] H.-W. Jeong, M.-R. Kim, K.-H. Son, M. Young Han, J.-H. Ha, M. Garnier, L. Meijer, B.-M. Kwon, Cinnamaldehydes inhibit cyclin dependent kinase 4/cyclin D1, Bioorg. Med. Chem. Lett. 10 (2000) 1819-1822.

[41] X.Q. Li, X.X. Liu, X.Y. Wang, Y.H. Xie, Q. Yang, Y.Y. Ding, W. Gao, S.W. Wang, Cinnamaldehyde derivatives inhibit Coxsackievirus B3-induced viral myocarditis, Biomol. Ther. 25 (2017) 279-287.

[42] F. Song, H. Li, J. Sun, S. Wang, Protective effects of cinnamic acid and cinnamic aldehyde on isoproterenol-induced acute myocardial ischemia in rats, $\mathrm{J}$. Ethnopharmacol. 150 (2013) 125-130.

[43] J.S. Hwa, Y.C. Jin, Y.S. Lee, J.H. Lee, Y.S. Ko, Y.S. Kim, Y.M. Kim, H.J. Kim, L.Y. Shi, T.M. Ngoc, K.H. Bae, K.C. Chang, 2-Methoxycinnamaldehyde from Cinnamomum cassia reduces rat myocardial ischemia and reperfusion injury in vivo due to HO-1 induction, J. Ethnopharmacol. 139 (2012) 605-615.

[44] Y.-L. Xue, H.-X. Shi, F. Murad, K. Bian, Vasodilatory effects of cinnamaldehyde and its mechanism of action in the rat aorta, Vasc. Health Risk Manag. 7 (2011) 273-280.

[45] A.M. Reddy, J.H. Seo, S.Y. Ryu, Y.S. Kim, Y.S. Kim, K.R. Min, Y. Kim, Cinnamaldehyde and 2-methoxycinnamaldehyde as NF-kB inhibitors from Cinnamomum cassia, Planta Med. 70 (2004) 823-827.

[46] S.-Y. Guo, J.-Y. Guo, H.-R. Huo, B.-S. Zhao, H.-B. Liu, L.-F. Li, Y.-Y. Ma, T.-L. Jiang, Cinnamaldehyde reduces IL- $1 \beta$-induced cyclooxygenase- 2 activity in rat cerebral microvascular endothelial cells, Eur. J. Pharmacol. 537 (2006) 174-180.

[47] J.-C. Liao, J.-S. Deng, C.-S. Chiu, W.-C. Hou, S.-S. Huang, P.-H. Shie, G.-J. Huang, Anti-inflammatory activities of Cinnamomum cassia constituents in vitro and in vivo, Evid. Based Complement. Alternat. Med. 2012 (2012) 429320.

[48] B.-M. Kwon, J.-Y. Kwon, S.-H. Hong, S.-D. Park, S.-G. Ahn, J.-H. Yoon, S.-A. Kim, 2'-Benzoyloxycinnamaldehyde inhibits nitric oxide production in lipopolysaccharide-stimulated RAW 264.7 cells via regulation of AP-1 pathway, Eur. J. Pharmacol. 696 (2012) 179-186.

[49] Q. Sun, B. Shang, L. Wang, Z. Lu, Y. Liu, Cinnamaldehyde inhibits fungal growth and aflatoxin B1 biosynthesis by modulating the oxidative stress response of Aspergillus flavus, Appl. Microbiol. Biotechnol. 100 (2016) 1355-1364.

[50] H. Li, Q. Shen, W. Zhou, H. Mo, D. Pan, L. Hu, Nanocapsular dispersion of cinnamaldehyde for enhanced inhibitory activity against aflatoxin production by Aspergillus flavus, Molecules (Basel, Switzerland) 20 (2015) 6022-6032.

[51] M.S.A. Khan, I. Ahmad, In vitro antifungal, anti-elastase and anti-keratinase activity of essential oils of Cinnamomum-Syzygium- and Cymbopogon-species against Aspergillus fumigatus and Trichophyton rubrum, Phytomedicine 19 (2011) 48-55.

[52] S.-Y. Wang, P.-F. Chen, S.-T. Chang, Antifungal activities of essential oils and their constituents from indigenous cinnamon (Cinnamomum osmophloeum) leaves against wood decay fungi, Bioresour. Technol. 96 (2005) 813-818.

[53] H. Hua, F. Xing, J.N. Selvaraj, Y. Wang, Y. Zhao, L. Zhou, X. Liu, Y. Liu, Inhibitory effect of essential oils on aspergillus ochraceus growth and ochratoxin a production, PLoS One 9 (2014) e108285.

[54] L. Wang, J. Jin, X. Liu, Y. Wang, Y. Liu, Y. Zhao, F. Xing, Effect of Cinnamaldehyde on morphological alterations of Aspergillus ochraceus and expression of key genes involved in Ochratoxin a biosynthesis, Toxins 10 (2018) 340.

[55] S. Shreaz, R. Bhatia, L.A. Khan, N. Khan, S. Muralidhar, S.F. Basir, N. Manzoor, Spice oil cinnamaldehyde exhibits potent anticandidal activity against fluconazole resistant clinical isolates, Fitoterapia 82 (2011) 1012-1020.

[56] S. Shreaz, R. Bhatia, L.A. Khan, N. Khan, I.K. Maurya, S.I. Ahmad, S. Muralidhar, N. Manzoor, Cinnamic aldehydes affect hydrolytic enzyme secretion and morphogenesis in oral Candida isolates, Microb. Pathog. 52 (2012) 251-258.

[57] H.C. Lee, S.S. Cheng, S.T. Chang, Antifungal property of the essential oils and their constituents from Cinnamomum osmophloeum leaf against tree pathogenic fungi, J. Sci. Food Agric. 85 (2005) 2047-2053.

[58] Q.-Y. Wei, J.-J. Xiong, H. Jiang, C. Zhang, W. Ye, The antimicrobial activities of the cinnamaldehyde adducts with amino acids, Int. J. Food Microbiol. 150 (2011) $164-170$.

[59] R. Bhatia, S. Shreaz, N. Khan, S. Muralidhar, S.F. Basir, N. Manzoor, L.A. Khan, Proton pumping ATPase mediated fungicidal activity of two essential oil components, J. Basic Microbiol. 52 (2012) 504-512.

[60] S. Morozumi, Isolation, purification, and antibiotic activity of o-methoxycinnamaldehyde from cinnamon, Appl. Environ. Microbiol. 36 (1978) 577-583.

[61] S. Shreaz, R. Bhatia, N. Khan, S. Muralidhar, N. Manzoor, L.A. Khan, Influences of cinnamic aldehydes on $\mathrm{H}+$ extrusion activity and ultrastructure of Candida, $\mathrm{J}$. Med. Microbiol. 62 (2013) 232-240.

[62] J.M. Quale, D. Landman, M.M. Zaman, S. Bumey, S.S. Sathe, In vitro activity of Cinnamomum zeylanicum against azole resistant and sensitive Candida species and a pilot study of cinnamon for Oral candidiasis, Am. J. Chin. Med. 24 (1996) 103-109.

[63] J. Jiang, M.P. Emont, H. Jun, X. Qiao, J. Liao, D.-i. Kim, J. Wu, Cinnamaldehyde induces fat cell-autonomous thermogenesis and metabolic reprogramming, Metabolism 77 (2017) 58-64.

[64] S. Camacho, S. Michlig, C. de Senarclens-Bezençon, J. Meylan, J. Meystre, M. Pezzoli, H. Markram, J. le Coutre, Anti-obesity and anti-hyperglycemic effects of cinnamaldehyde via altered ghrelin secretion and functional impact on food intake and gastric emptying, Sci. Rep. 5 (2015) 7919.

[65] Y. Tamura, Y. Iwasaki, M. Narukawa, T. Watanabe, Ingestion of Cinnamaldehyde, a TRPA1 agonist, reduces visceral fats in mice fed a high-fat and high-sucrose diet, J. Nutr. Sci. Vitaminol 58 (2012) 9-13.

[66] Y. Masamoto, F. Kawabata, T. Fushiki, Intragastric administration of TRPV1,
TRPV3, TRPM8, and TRPA1 agonists modulates autonomic thermoregulation in different manners in mice, Biosci. Biotechnol. Biochem. 73 (2009) 1021-1027.

[67] Y. Iwasaki, M. Tanabe, K. Kobata, T. Watanabe, TRPA1 agonists-Allyl Isothiocyanate and Cinnamaldehyde-induce adrenaline secretion, Biosci. Biotechnol. Biochem. 72 (2008) 2608-2614.

[68] S. Michlig, J.M. Merlini, M. Beaumont, M. Ledda, A. Tavenard, R. Mukherjee, S. Camacho, J. le Coutre, Effects of TRP channel agonist ingestion on metabolism and autonomic nervous system in a randomized clinical trial of healthy subjects, Sci. Rep. 6 (2016) 20795.

[69] C. Pandit, K.R. Anilakumar, Cold adaptive thermogenesis following consumption of certain pungent spice principles: a validation study, J. Therm. Biol. 64 (2017) 35-40.

[70] G. Brackman, S. Celen, U. Hillaert, S. Van Calenbergh, P. Cos, L. Maes, H.J. Nelis, T. Coenye, Structure-activity relationship of Cinnamaldehyde Analogs as inhibitors of AI-2 based quorum sensing and their effect on virulence of Vibrio spp, PLoS One 6 (2011) e16084.

[71] L.R. Sadofsky, A.N. Boa, S.A. Maher, M.A. Birrell, M.G. Belvisi, A.H. Morice, TRPA1 is activated by direct addition of cysteine residues to the N-hydroxysuccinyl esters of acrylic and cinnamic acids, Pharmacol. Res. 63 (2011) 30-36.

[72] A. Autelitano, A. Minassi, A. Pagani, O. Taglialatela-Scafati, G. Appendino, The reaction of cinnamaldehyde and cinnam(o)yl derivatives with thiols, Acta Pharm. Sin. B 7 (2017) 523-526.

[73] C. Avonto, C. Avonto, O. Taglialatela-Scafati, F. Pollastro, A. Minassi, An NMR spectroscopic method to identify and classify Thiol-trapping agents: revival of Michael acceptors for drug discovery? Angew. Chem. (International Ed.) 50 (2011) 467-471.

[74] H. Ye, S. Shen, J. Xu, S. Lin, Y. Yuan, G.S. Jones, Synergistic interactions of cinnamaldehyde in combination with carvacrol against food-borne bacteria, Food Control 34 (2013) 619-623.

[75] A. Upadhyay, K. Arsi, B.R. Wagle, I. Upadhyaya, S. Shrestha, A.M. Donoghue, D.J. Donoghue, Trans-Cinnamaldehyde, Carvacrol, and Eugenol reduce campylobacter jejuni colonization factors and expression of virulence genes in vitro, Front. Microbiol. 8 (2017) 713.

[76] H. Wang, H. Yuan, S. Li, Z. Li, M. Jiang, Synthesis, antimicrobial activity of Schiff base compounds of cinnamaldehyde and amino acids, Bioorg. Med. Chem. Lett. 26 (2016) 809-813.

[77] T.-T. Liu, Y.-W. Tseng, T.-S. Yang, Functionalities of conjugated compounds of $\gamma$ aminobutyric acid with salicylaldehyde or cinnamaldehyde, Food Chem. 190 (2016) 1102-1108.

[78] Q. Shen, W. Zhou, L. Hu, Y. Qi, H. Ning, J. Chen, H. Mo, Bactericidal activity of alpha-bromocinnamaldehyde against persisters in Escherichia coli, PLoS One 12 (2017) e0182122.

[79] X. Li, S. Ma, Advances in the discovery of novel antimicrobials targeting the assembly of bacterial cell division protein FtsZ, Eur. J. Med. Chem. 95 (2015) 1-15.

[80] D. Panda, D. Bhattacharya, Q.H. Gao, P.M. Oza, H.Y.J. Lin, B. Hawkins, D.E. Hibbs, P.W. Groundwater, Identification of agents targeting FtsZ assembly, Future Med. Chem. 8 (2016) 1111-1132.

[81] K. Haranahalli, S. Tong, I. Ojima, Recent advances in the discovery and devel opment of antibacterial agents targeting the cell-division protein FtsZ, Bioorg. Med. Chem. 24 (2016) 6354-6369.

[82] K.A. Hurley, T.M.A. Santos, G.M. Nepomuceno, V. Huynh, J.T. Shaw, D.B. Weibel, Targeting the bacterial division protein FtsZ, J. Med. Chem. 59 (2016) 6975-6998.

[83] K. Kumar, D. Awasthi, W.T. Berger, P.J. Tonge, R.A. Slayden, I. Ojima, Discovery of anti-TB agents that target the cell-division protein FtsZ, Future Med. Chem. 2 (2010) 1305-1323.

[84] S. Ma, S. Ma, The development of FtsZ inhibitors as potential antibacterial agents, ChemMedChem 7 (2012) 1161-1172.

[85] P. Domadia, S. Swarup, A. Bhunia, J. Sivaraman, D. Dasgupta, Inhibition of bacterial cell division protein FtsZ by cinnamaldehyde, Biochem. Pharmacol. 74 (2007) 831-840.

[86] S. Tripathy, S.K. Sahu, FtsZ inhibitors as a new genera of antibacterial agents, Bioorg. Chem. 91 (2019) 103169.

[87] X. Li, J. Sheng, G. Huang, R. Ma, S. Ma, F. Yin, D. Song, C. Zhao, Design, synthesis and antibacterial activity of cinnamaldehyde derivatives as inhibitors of the bacterial cell division protein FtsZ, Eur. J. Med. Chem. 97 (2015) 32-41.

[88] P. Jia, Y.J. Xue, X.J. Duan, S.H. Shao, Effect of cinnamaldehyde on biofilm formation and sarA expression by methicillin-resistant Staphylococcus aureus, Lett. Appl. Microbiol. 53 (2011) 409-416.

[89] K.R. Zodrow, J.D. Schiffman, M. Elimelech, Biodegradable polymer (PLGA) coat ings featuring cinnamaldehyde and carvacrol mitigate biofilm formation, Langmuir 28 (2012) 13993-13999.

[90] U. Römling, C. Balsalobre, Biofilm infections, their resilience to therapy and innovative treatment strategies, J. Intern. Med. 272 (2012) 541-561.

[91] H. Koo, R.N. Allan, R.P. Howlin, P. Stoodley, L. Hall-Stoodley, Targeting microbial biofilms: current and prospective therapeutic strategies, Nat. Rev. Microbiol. 15 (2017) 740-755.

[92] B. Kot, J. Wicha, M. Piechota, K. Wolska, A. Gruzewska, Antibiofilm activity of trans-cinnamaldehyde, p-coumaric, and ferulic acids on uropathogenic Escherichia coli, Turkish J. Med. Sci. 45 (2015) 919-924.

[93] M.A.R. Amalaradjou, A. Narayanan, S.A. Baskaran, K. Venkitanarayanan, Antibiofilm effect of trans-Cinnamaldehyde on Uropathogenic Escherichia coli, J. Urol. 184 (2010) 358-363.

[94] C. Niu, E.S. Gilbert, Colorimetric method for identifying plant essential oil components that affect biofilm formation and structure, Appl. Environ. Microbiol. 70 (2004) 6951-6956.

[95] Y.-G. Kim, S.-I. Kim, J.-H. Lee, J. Lee, K.-H. Baek, Cinnamon bark oil and its 
components inhibit biofilm formation and toxin production, Int. J. Food Microbiol. 195 (2015) 30-39.

[96] B. Kot, K. Wierzchowska, A. Grużewska, D. Lohinau, The effects of selected phytochemicals on biofilm formed by five methicillin-resistant Staphylococcus aureus, Nat. Prod. Res. 32 (2018) 1299-1302.

[97] N.L. Kavanaugh, K. Ribbeck, Selected antimicrobial essential oils eradicate Pseudomonas spp. and Staphylococcus aureus biofilms, Appl. Environ. Microbiol. 78 (2012) 4057-4061.

[98] P.E. Budri, N.C.C. Silva, E.C.R. Bonsaglia, A. Fernandes, J.P. Araújo, J.T. Doyama, J.L. Gonçalves, M.V. Santos, D. Fitzgerald-Hughes, V.L.M. Rall, Effect of essential oils of Syzygium aromaticum and Cinnamomum zeylanicum and their major components on biofilm production in Staphylococcus aureus strains isolated from milk of cows with mastitis, J. Dairy Sci. 98 (2015) 5899-5904.

[99] T. Li, J. Li, D. Wang, N. Liu, Y. Ma, T. Ding, Y. Mei, Inhibition of quorum sensingcontrolled virulence factors and biofilm formation in Pseudomonas fluorescens by cinnamaldehyde, Int. J. Food Microbiol. 269 (2018) 98-106.

[100] M.A.R. Amalaradjou, K. Venkitanarayanan, Effect of trans-cinnamaldehyde on inhibition and inactivation of Cronobacter sakazakii biofilm on abiotic surfaces, J. Food Prot. 74 (2011) 200-208.

[101] M. Albano, B.P. Crulhas, F.C.B. Alves, A.F.M. Pereira, B.F.M.T. Andrade, L.N. Barbosa, A. Furlanetto, L.P.D.S. Lyra, V.L.M. Rall, A.F. Júnior, Antibacterial and anti-biofilm activities of cinnamaldehyde against S. epidermidis, Microbial Pathog. 126 (2019) 231-238.

[102] R.M. Beema Shafreen, C. Selvaraj, S.K. Singh, S. Karutha Pandian, In silico and in vitro studies of cinnamaldehyde and their derivatives against LuxS in streptococcus pyogenes: effects on biofilm and virulence genes, J. Mol. Recognit. 27 (2014) 106-116.

[103] A.F. Silva, A.R. dos Santos, D.A. Coelho Trevisan, A.B. Ribeiro, P.A. Zanetti Campanerut-Sá, C. Kukolj, E.M. de Souza, R.F. Cardoso, T.I. Estivalet Svidzinski, B.A. de Abreu Filho, M.M. Junior, J.M. Graton Mikcha, Cinnamaldehyde induces changes in the protein profile of Salmonella Typhimurium biofilm, Res. Microbiol. 169 (2018) 33-43.

[104] D.F. Rodrigues, M. Elimelech, Role of type 1 fimbriae and mannose in the development of Escherichia coli K12 biofilm: from initial cell adhesion to biofilm formation, Biofouling 25 (2009) 401-411.

[105] C. Niu, S. Afre, E.S. Gilbert, Subinhibitory concentrations of cinnamaldehyde interfere with quorum sensing, Lett. Appl. Microbiol. 43 (2006) 489-494.

[106] G. Brackman, T. Defoirdt, C. Miyamoto, P. Bossier, S. Van Calenbergh, H. Nelis, $\mathrm{T}$. Coenye, Cinnamaldehyde and cinnamaldehyde derivatives reduce virulence in Vibrio spp. by decreasing the DNA-binding activity of the quorum sensing response regulator LuxR, BMC Microbiol. 8 (2008) 149.

[107] P.S.X. Yap, T. Krishnan, K.-G. Chan, S.H.E. Lim, Antibacterial mode of action of Cinnamomum verum bark essential oil, alone and in combination with Piperacillin, against a multi-drug-resistant Escherichia coli strain, J. Microbiol. Biotechnol. 25 (2015) 1299-1306.

[108] T. Xue, L. Zhao, B. Sun, LuxS/AI-2 system is involved in antibiotic susceptibility and autolysis in Staphylococcus aureus NCTC 8325, Int. J. Antimicrob. Agents 41 (2013) 85-89.

[109] J. Rao, B. Chen, D.J. McClements, Improving the efficacy of essential oils as antimicrobials in foods: mechanisms of action, Annu. Rev. Food Sci. Technol. 10 (2019) 365-387.

[110] Y. Zhang, X. Liu, Y. Wang, P. Jiang, S. Quek, Antibacterial activity and mechanism of cinnamon essential oil against Escherichia coli and Staphylococcus aureus, Food Control 59 (2016) 282-289.

[111] M. Turgis, J. Han, S. Caillet, M. Lacroix, Antimicrobial activity of mustard essential oil against Escherichia coli O157:H7 and Salmonella typhi, Food Control 20 (2009) 1073-1079.
[112] R. Moghimi, L. Ghaderi, H. Rafati, A. Aliahmadi, D.J. McClements, Superior antibacterial activity of nanoemulsion of Thymus daenensis essential oil against E. coli, Food Chem. 194 (2016) 410-415.

[113] M. Oussalah, S. Caillet, M. Lacroix, Mechanism of action of Spanish oregano, Chinese cinnamon, and Savory essential oils against cell membranes and walls of Escherichia coli O157:H7 and Listeria monocytogenes, J. Food Prot. 69 (2006) 1046-1055.

[114] P. Breeuwer, J. Drocourt, F.M. Rombouts, T. Abee, A novel method for continuous determination of the intracellular $\mathrm{pH}$ in Bacteria with the internally conjugated fluorescent probe 5 (and 6-)-Carboxyfluorescein Succinimidyl Ester, Appl. Environ. Microbiol. 62 (1996) 178-183.

[115] S.M.Z. Hossain, B. Bojko, J. Pawliszyn, Automated SPME-GC-MS monitoring of headspace metabolomic responses of $\mathrm{E}$. coli to biologically active components extracted by the coating, Anal. Chim. Acta 776 (2013) 41-49.

[116] F. Mousavi, B. Bojko, V. Bessonneau, J. Pawliszyn, Cinnamaldehyde characterization as an antibacterial agent toward E. coli metabolic profile using 96-blade solid-phase microextraction coupled to liquid chromatography-mass spectrometry, J. Proteome Res. 15 (2016) 963-975.

[117] W.-R. Diao, Q.-P. Hu, H. Zhang, J.-G. Xu, Chemical composition, antibacterial activity and mechanism of action of essential oil from seeds of fennel (Foeniculum vulgare Mill.), Food Control 35 (2014) 109-116.

[118] S. Cox, C. Mann, J. Markham, J. Gustafson, J. Warmington, S. Wyllie, Determining the antimicrobial actions of tea tree oil, Molecules 6 (2001) 87-91.

[119] T.-F. He, L.-H. Wang, D. Niu, Q. Wen, X.-A. Zeng, Cinnamaldehyde inhibit Escherichia coli associated with membrane disruption and oxidative damage, Arch. Microbiol. 201 (2019) 451-458.

[120] A.-F. Miller, Superoxide dismutases: ancient enzymes and new insights, FEBS Lett. 586 (2012) 585-595.

[121] S. Shen, T. Zhang, Y. Yuan, S. Lin, J. Xu, H. Ye, Effects of cinnamaldehyde on Escherichia coli and Staphylococcus aureus membrane, Food Control 47 (2015) 196-202.

[122] R. Mempin, H. Tran, C. Chen, H. Gong, K. Kim Ho, S. Lu, Release of extracellular ATP by bacteria during growth, BMC Microbiol. 13 (2013) 301.

[123] I.M. Helander, H.L. Alakomi, K. Latva-Kala, T. Mattila-Sandholm, I. Pol, E.J. Smid, L.G.M. Gorris, V.A. Wright, Characterization of the action of selected essential oil components on Gram-negative bacteria, J. Agric. Food Chem. 46 (1998) 3590-3595.

[124] S.W. Nowotarska, K. Nowotarski, I.R. Grant, C.T. Elliott, M. Friedman, C. Situ, Mechanisms of antimicrobial action of cinnamon and oregano oils, cinnamaldehyde, carvacrol, 2,5-dihydroxybenzaldehyde, and 2-hydroxy-5-methoxybenzaldehyde against Mycobacterium avium subsp. paratuberculosis (Map), Foods (Basel, Switzerland) 6 (2017) 72.

[125] J. Usta, S. Kreydiyyeh, P. Barnabe, Y. Bou-Moughlabay, H. Nakkash-Chmaisse, Comparative study on the effect of cinnamon and clove extracts and their main components on different types of ATPases, Hum. Exp. Toxicol. 22 (2003) 355-362.

[126] P.L. Pedersen, Transport ATPases into the year 2008: a brief overview related to types, structures, functions and roles in health and disease, J. Bioenerg. Biomembr. 39 (2007) 349-355.

[127] J. Sikkema, D.J.A.M. Bont, B. Poolman, Mechanisms of membrane toxicity of hydrocarbons, Microbiological Sciences 59 (1995) 201-222.

[128] A.O. Gill, R.A. Holley, Inhibition of membrane bound ATPases of Escherichia coli and Listeria monocytogenes by plant oil aromatics, Int. J. Food Microbiol. 111 (2006) 170-174.

[129] A. Doyle A., T. Krämer, K. Kavanagh, J. Stephens C., Cinnamaldehydes: Synthesis, antibacterial evaluation, and the effect of molecular structure on antibacterial activity. Results in Chemistry (2019), https://doi.org/10.1016/j.rechem.2019. 100013 In press. 